Journal of Sandwich Structures and Materials

\title{
Analytical solution of some delamination scenarios in thick plates
}

\section{András Szekrényes}

\begin{abstract}
The first-, second- and third-order shear deformation plate theories are applied in this work to model thick rectangular sandwich plates with through-width delamination. The models are based on the concept of the four equivalent single layers and the system of exact kinematic conditions. Three different scenarios are considered: the failure of the core, the delamination between the top facesheet and the core, and finally, the case when the delamination takes place in the local midplane of the top facesheet. A general model is derived and applied to sandwich plates with Lévy type boundary conditions. The governing equations are summarized and the state-space model of the system is created. The mechanical fields are calculated and compared to finite element results. The comparison shows that the first-order sandwich plate model is inaccurate, on the other hand, the second- and third-order theories capture very well the mechanical fields compared to finite element results. The J-integral distribution is also calculated along the delamination front and it is concluded that the third-and second-order models give very good approximations of the results by finite element analysis and the virtual crack closure technique.
\end{abstract}

\section{Keywords}

Delamination, higher-order sandwich plate theory, Lévy plate, J-integral, mixed-mode II/III fracture 


\section{Introduction}

The delamination in lightweight sandwich structures reduces significantly the strength and the stiffness and alters the dynamic behaviour, e.g. [1]. Delamination and debonding - in general - is induced by impact [2-10], blast loading [11], drilling and perforation [12,13] or indentations [14-16] or other special loads $[17,18]$. Moreover, delaminations can change significantly the buckling behaviour of laminated structures [19-24]. In accordance with the literature, the interlaminar fracture of sandwich materials - similarly to laminated composites - is investigated under mode-I [25-30] mode-II [25] and mixed-mode I/II [25,31-33] conditions. These cases are summarized in detail in [34]. In the near past numerical and experimental studies on the mode-III [35,36] and mixed modes II/III, I/II/III [37-39] delamination of sandwich beams were conducted. Generally, sandwich panels and plates are fabricated by using foam [40] - which has significant damping [41] - or metal honeycomb [28,42-44] as core material, while facesheets are made from composite or metal plates [34]. Most of the relevant works are related to the facesheet-core debond characterization, however, there are also other scenarios, like the failure of the core and the face delamination [34]. In fact only few works are available internationally which focus on the delamination analysis of sandwich plates. On the contrary, many plate theories are developed for sandwich panels and plates. The traditional Kirchhoff theory [45] is applicable only to sandwich structures subjected to membrane stress state [34]. The simplest theory of sandwich beams and plates is based on the 'anti-plane core' concept and assumes zero normal stress in the core material, at the same time, the shear stress in the core is very important to be considered (first-order shear analysis) [34,46,47]. Later it was recognized that the soft-core sandwich structures require to take the transverse elasticity of the core into account. Therefore, numerous plate theories have been developed and applied to sandwich structures. Among others, the elasticity solution [34,48], higher-order and layerwise theories [49,50-54] and zig-zag theories [55-58] should be mentioned. These theories are also applied to free vibration and buckling problems $[13,55,59-72]$, to develop Finite Element (FE) models and types [73-78] moreover to solve issues related to nonlinear effects [79-81], transient dynamic analysis [82-86], dynamic stability [87], deformation analysis of test specimens [88] and functionally graded core materials [89-97].

In most of the papers above, the analysis is carried out on perfect sandwich structures, or if material defects are considered, then the geometry is restricted to that of beams. The aim of the present work is to develop a layerwise analytical model for the analysis of delaminations in thick sandwich plates based on HigherOrder Shear Deformation Theories (HSDT). Previously, similar models have already been developed and applied to delaminated composite plates by the author using the Classical Laminated Plate Theory (CLPT) [98], the First(FSDT) [99], the Second- (SSDT) [100,101] and Third-Order Shear Deformation Theories (TSDT) [102] as well as Reddy third-order theory [103,104]. The first attempts involved the application of two equivalent single layers (ESL) over the thickness, later refined models have been created by using four ESLs [105,106] 
leading to more accurate results for plates, wherein the delamination is close to the free boundary surface. The mechanical model developed previously is applied to create a model for delaminated sandwich plates. Three different scenarios are considered: the core failure (Scenario I), the face-core debond (Scenario II) and the face delamination (Scenario III). The method of four ESLs is applied to these cases by using assumed displacement field model based on the HSDT and the system of exact kinematic conditions (SEKC). The governing equations of the model are derived and solved by using the Lévy plate formulation. Delaminated sandwich plates with uniformly distributed load were analysed and the state-space model was created to solve the system of Differential Equations (DEs). The FE models were created for each scenario and the analytical results were compared to the numerical ones.

\section{The SEKC}

The basic concept is that the sandwich plate is modelled by four ESLs. Figure 1(a) shows the deformation of the cross sections in the vicinity of the delamination tip in the $X-Z$ plane for the core failure scenario (Scenario I). In the $Y-Z$ plane, the deformation is similar $[105,106]$. The top and bottom facesheets are captured by an ESL and two ESLs are applied to the core. Interface plane 2-3 is the plane of the delamination, the delamination front is straight and parallel to the $Y$ direction. The thicknesses are denoted by $t_{i}, i=1 \ldots 4$, where $i$ is the actual ESL index. Figure 1(b) shows the shear strain distribution, which is discontinuous (piecewise constant) in accordance with the FSDT. Moreover, the SSDT and TSDT solutions make it possible to match the shear strains in the core; however, these are still discontinuous at interface planes 1-2 and 3-4. The assumed displacement field of each ESL is [107-110]:

$$
\begin{aligned}
u_{(i)}\left(x, y, z^{(i)}\right) & =u_{0}(x, y)+u_{0 i}(x, y)+\theta_{(x) i}(x, y) z^{(i)}+\phi_{(x) i}(x, y)\left[z^{(i)}\right]^{2}+\lambda_{(x) i}(x, y)\left[z^{(i)}\right]^{3}, \\
v_{(i)}\left(x, y, z^{(i)}\right) & =v_{0}(x, y)+v_{0 i}(x, y)+\theta_{(y) i}(x, y) z^{(i)}+\phi_{(y) i}(x, y)\left[z^{(i)}\right]^{2}+\lambda_{(y) i}(x, y)\left[z^{(i)}\right]^{3}, \\
w_{(i)}(x, y) & =w(x, y)
\end{aligned}
$$

where $i$ is the index of the actual ESL, $z^{(i)}$ is the local through thickness coordinate of the $i$ th ESL, $u_{0}, v_{0}$ are the global, $u_{0 i}, v_{0 i}$ are the local membrane displacements; moreover, $\theta$ means the rotations of the cross sections about the $X$ and $Y$ axes (refer to Figure 1(a)), $\phi$ denotes the second-order, $\lambda$ represents the third-order terms in the displacement functions. Finally, $w_{(i)}$ is the transverse deflection function. Equation (1) will be applied equally to the undelaminated and delaminated portions and the continuity between these parts will be established. In this work, only shear deformable plate models are developed, in other words, the deflection is 
inextensible in the through-thickness direction and assumes $w_{(i)}(x, y)=w(x, y)$. It was assumed that there is no crack opening, i.e. a constrained mode model was applied with mixed-mode II/III conditions [111,112]. The displacement functions of FSDT and SSDT can be obtained by reducing equation (1) and taking $\phi_{(x) i}=\phi_{(y) i}=0$ and $\lambda_{(x) i}=\lambda_{(y) i}=0$, respectively $[113,114]$. The displacement field given by equation (1) is associated to each ESL.

The displacement vector field for the $i$ th ESL is $\mathbf{u}_{(i)}=\left(\begin{array}{lll}u_{(i)} & v_{(i)} & w_{(i)}\end{array}\right)^{T}$. The kinematic continuity between the displacement fields of adjacent ESLs is established by the SEKC, which was originally developed in $[99,101,104-106]$ for delaminated composite plates. The first set of conditions formulates the continuity of the in-plane and transverse displacements between the neighbouring plies as (refer to Figure 1):

$$
\left.\left(u_{(i)}, v_{(i)}, w_{(i)}\right)\right|_{z^{(i)}=t_{i} / 2}=\left.\left(u_{(i+1)}, v_{(i+1)}, w_{(i+1)}\right)\right|_{z^{(i+1)}=-t_{i+1} / 2}
$$

where $t_{i}$ is the thickness of the specified layer. It has to be noted that the result of equation (2) was applied in [115] and [116]; however, the presented equations are valid only for the FSDT. On the contrary, equation (2) is more general and applicable to any plate theory. Moreover, there are large number of works referred to in the book of Reddy [117] applying displacement continuity between the layers. Those works apply full layerwise models to perfect plates, in contrast with this work, which deals with the semi-layerwise analysis of delaminated sandwich plates. The second set of conditions defines the global membrane displacements $\left(u_{0}, v_{0}\right)$ at the reference plane of the actual region. If the coordinate
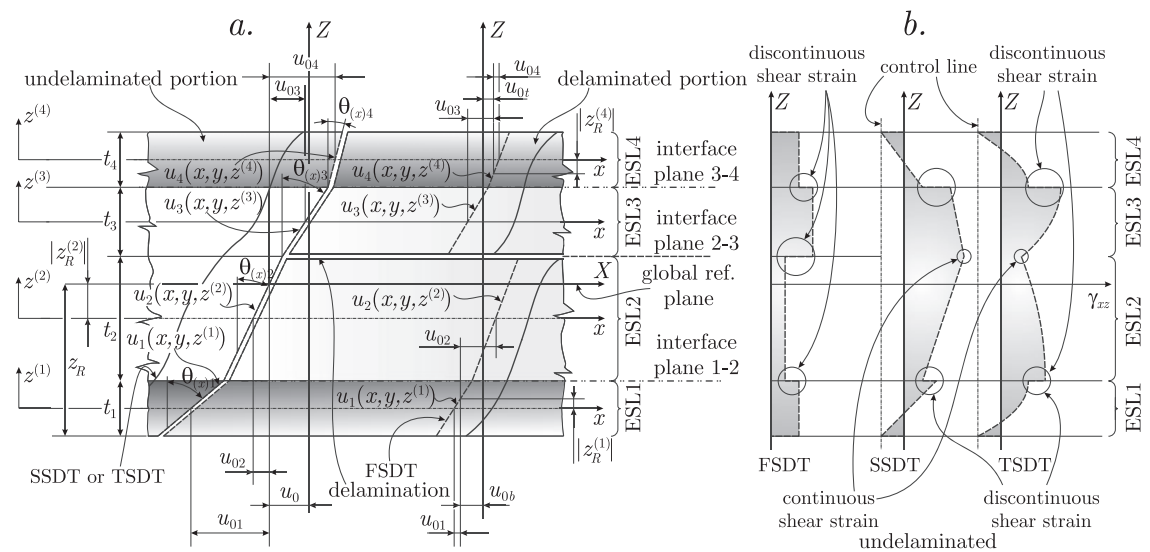

Figure I. Cross sections and parameters of the delaminated sandwich plate in the $X-Z$ plane for core-core failure (Scenario I). 
of the global reference plane is $z_{R}^{(i)}$ and is located in the $i$ th layer, then the conditions become:

$$
\left.u_{(i)}\right|_{z^{(i)}=z_{R}^{(i)}}-u_{0}=0,\left.\quad v_{(i)}\right|_{z^{(i)}=z_{R}^{(i)}}-v_{0}=0
$$

The two sets of conditions given by equations (2) and (3) are sufficient to develop semi-layerwise models using the FSDT. If the SSDT or TSDT is applied, then we can impose the shear strain continuity at the interface (or perturbation) planes. In accordance with Figure 1(b), these conditions are formulated as:

$$
\left.\left(\gamma_{x z(i)}, \gamma_{y z(i)}\right)\right|_{z^{(i)}=t_{i} / 2}=\left.\left(\gamma_{x z(i+1)}, \gamma_{y z(i+1)}\right)\right|_{z^{(i+1)}=-t_{i+1} / 2}
$$

It has to be mentioned that in general layerwise models assume continuous shear stresses at the interfaces [117]. However, the stress continuity results in a locking (over-constraining) problem in delaminated plates $[105,106]$. For the TSDT theory, one more set of conditions is reasonable to introduce. The imposition of continuity of derivatives of the shear strain [106] prevents the unwanted oscillations (and the too large compliance) in the shear stress distributions (see Figure 1):

$$
\left.\left(\frac{\partial \gamma_{x z(i)}}{\partial z^{(i)}}, \frac{\partial \gamma_{y z(i)}}{\partial z^{(i)}}\right)\right|_{z^{(i)}=t_{i} / 2}=\left.\left(\frac{\partial \gamma_{x z(i+1)}}{\partial z^{(i+1)}}, \frac{\partial \gamma_{y z(i+1)}}{\partial z^{(i+1)}}\right)\right|_{z^{(i+1)}=-t_{i+1} / 2}
$$

An important addition to equations (2) to (5) is the so-called Shear Strain Control Condition (SSCC [105]). The set of conditions applied is:

$$
\left.\left(\gamma_{x z(l)}, \gamma_{y z(l)}\right)\right|_{z^{(l)}=-t_{l} / 2}=\left.\left(\gamma_{x z(m)}, \gamma_{y z(m)}\right)\right|_{z^{(m)}=t_{m} / 2}
$$

where $l$ and $m$ denote ESLs at the boundaries, where the shear strains are equal to each other and $m>l$ always. In accordance with Reddy theory [117], the top and bottom surfaces of the plate are traction-free (zero shear stresses). If the system is modelled by four ESLs, the traction-free conditions lead to overconstraining (or stiffening) of the model and wrong results are obtained. Therefore, instead of imposing zero stresses at the free surfaces, we impose the identical shear strain values at the boundary planes by equation (6). Essentially, the SSCC is applicable only if at least four ELSs and the SDDT or TSDT are applied. In the following section, the displacement fields and applied conditions are discussed for the undelaminated and delaminated regions separately.

\section{Undelaminated part}

Apparently, the deflections are the same in each ESL. Using the conditions in equations (2) to (6), it is possible to have the following form of the 
displacement components:

$$
\begin{aligned}
u_{(i)} & =u_{0}+\left(K_{i j}^{(0)}+K_{i j}^{(1)} z^{(i)}+K_{i j}^{(2)}\left[z^{(i)}\right]^{2}+K_{i j}^{(3)}\left[z^{(i)}\right]^{3}\right) \psi_{(x) j}, \quad i=1 . .4, \\
v_{(i)} & =v_{0}+\left(K_{i j}^{(0)}+K_{i j}^{(1)} z^{(i)}+K_{i j}^{(2)}\left[z^{(i)}\right]^{2}+K_{i j}^{(3)}\left[z^{(i)}\right]^{3}\right) \psi_{(y) j}, \quad i=1 . .4, \\
w_{(i)} & =w(x, y), \quad i=1 . .4
\end{aligned}
$$

where $\psi$ is the vector of primary parameters depending on the applied theory. In the sequel, we discuss the conditions and equations separately for each theory.

First-order plate theory. For the FSDT model, the quadratic and cubic terms in equation (7) vanish, and so $K_{i j}^{(2)}=K_{i j}^{(3)}=0$. For a four-layer FSDT model shown in Figure 1(a) and (b), the SEKC conditions are applied in accordance with Table 1 depending on the delamination scenario. For the undelaminated part, the equations become:

$$
\begin{aligned}
\left.\left(u_{1}, v_{1}, w_{1}\right)\right|_{z^{(1)}=t_{1} / 2} & =\left.\left(u_{2}, v_{2}, w_{2}\right)\right|_{z^{(2)}=-t_{2} / 2}, \\
\left.\left(u_{2}, v_{2}, w_{2}\right)\right|_{z^{(2)}=t_{2} / 2} & =\left.\left(u_{3}, v_{3}, w_{3}\right)\right|_{z^{(3)}=-t_{3} / 2}, \\
\left.\left(u_{3}, v_{3}, w_{3}\right)\right|_{z^{(3)}=t_{3} / 2} & =\left.\left(u_{4}, v_{4}, w_{4}\right)\right|_{z^{(4)}=-t_{4} / 2}, \\
\left.\left(u_{2}, v_{2}\right)\right|_{z^{(2)}=z_{R}^{(2)}} & =\left(u_{0}(x, y), v_{0}(x, y)\right)
\end{aligned}
$$

\begin{tabular}{|c|c|c|c|c|}
\hline $\begin{array}{l}\text { Equation } \\
\text { (2) }\end{array}$ & $\begin{array}{l}\text { Equation } \\
\text { (3) }\end{array}$ & $\begin{array}{l}\text { Equation } \\
\text { (4) }\end{array}$ & $\begin{array}{l}\text { Equation } \\
\text { (5) }\end{array}$ & $\begin{array}{l}\text { Equation } \\
\text { (6) }\end{array}$ \\
\hline$i=I, i=2, i=3$ & $i=2$ & - & - & - \\
\hline$i=1, i=2, i=3$ & $i=2$ & $i=2$ & - & $\mathrm{I}=\mathrm{I}, \mathrm{m}=4$ \\
\hline $\mathrm{i}=\mathrm{I}, \mathrm{i}=2, \mathrm{i}=3$ & $\mathrm{i}=2$ & $i=2$ & $i=2$ & $\mathrm{I}=\mathrm{I}, \mathrm{m}=4$ \\
\hline$i=1, i=2, i=3$ & $i=2$ & - & - & - \\
\hline$i=1, i=2, i=3$ & $i=2$ & $i=3$ & - & $\mathrm{I}=\mathrm{I}, \mathrm{m}=4$ \\
\hline$i=I, i=2, i=3$ & $i=2$ & $i=3$ & $i=3$ & $\mathrm{I}=\mathrm{I}, \mathrm{m}=4$ \\
\hline
\end{tabular}

where $z_{R}^{(2)}=\left(t_{1}+t_{2}+t_{3}+t_{4}\right) / 2-t_{1}-t_{2} / 2$ is the location of the reference plane (midplane) of the undelaminated part with respect to the midplane of ESL2 (refer to Figure 1). By using these conditions, we can eliminate the local membrane displacements denoted by $u_{0 i}$ and $v_{0 i}(i=1 . .4)$ in equation (1). The vector of

Table I. The set of SEKC equations applied to FSDT, SSDT and TSDT - Undelaminated part. 
primary parameters contains the rotations only:

$$
\psi_{(p)}=\left(\begin{array}{llll}
\theta_{(p) 1} & \theta_{(p) 2} & \theta_{(p) 3} & \theta_{(p) 4}
\end{array}\right)^{T}, \quad p=x, y
$$

The constants of the multiplicator matrices denoted by $K_{i j}$ are listed in Table 2 (core-core and face-core scenarios) and Table 3 (face-face scenario).

Second-order plate theory. For the second-order model, the cubic terms in equation (1) vanish and thus $K_{i j}^{(3)}=0$. The SEKC conditions applied are presented in Table 1 for each scenario. In this case, the vector of primary parameters is given by:

$$
\psi_{(p)}=\left(\begin{array}{llllll}
\theta_{(p) 1} & \theta_{(p) 2} & \theta_{(p) 3} & \theta_{(p) 4} & \phi_{(p) 2} & \phi_{(p) 4}
\end{array}\right)^{T}, \quad p=x, y
$$

Table 2. Multiplicator matrix elements for the FSDT theory - Scenarios I and II: Core-core and face-core delamination.

\begin{tabular}{llllllllll}
\hline & \multicolumn{3}{c}{ Undelaminated } & \multicolumn{2}{c}{ Delaminated } & \multicolumn{3}{c}{ Undelaminated } & \multicolumn{3}{c}{ Delaminated } \\
\cline { 2 - 9 }$[\mathrm{i}, \mathrm{j}]$ & $K_{i j}^{(0)}$ & $K_{i j}^{(1)}$ & $K_{i j}^{(0)}$ & $K_{i j}^{(1)}$ & {$[i, j]$} & $K_{i j}^{(0)}$ & $K_{i j}^{(1)}$ & $K_{i j}^{(0)}$ & $K_{i j}^{(1)}$ \\
\hline$[1,1]$ & $-\frac{1}{2} t_{1}$ & 1 & $-z_{R}^{(1)}$ & 1 & {$[3,1]$} & 0 & 0 & 0 & 0 \\
{$[1,2]$} & $-z_{R}^{(2)}-\frac{1}{2} t_{2}$ & 0 & 0 & 0 & {$[3,2]$} & $-z_{R}^{(2)}-\frac{1}{2} t_{2}$ & 0 & 0 & 0 \\
{$[1,3]$} & 0 & 0 & 0 & 0 & {$[3,3]$} & $\frac{1}{2} t_{3}$ & 1 & $-\frac{1}{2} t_{3}$ & 1 \\
{$[1,4]$} & 0 & 0 & 0 & 0 & {$[3,4]$} & 0 & 0 & $-z_{R}^{(4)}-\frac{1}{2} t_{4}$ & 0 \\
{$[2,1]$} & 0 & 0 & $-z_{R}^{(2)}+\frac{1}{2} t_{1}$ & 0 & {$[4,1]$} & 0 & 0 & 0 & 0 \\
{$[2,2]$} & $-z_{R}^{(2)}$ & 1 & $\frac{1}{2} t_{2}$ & 1 & {$[4,2]$} & $-z_{R}^{(2)}+\frac{1}{2} t_{2}$ & 0 & 0 & 0 \\
{$[2,3]$} & 0 & 0 & 0 & 0 & {$[4,3]$} & $t_{3}$ & 0 & 0 & 0 \\
{$[2,4]$} & 0 & 0 & 0 & 0 & {$[4,4]$} & $\frac{1}{4} t_{4}$ & 1 & $-z_{R}^{(4)}$ & 1 \\
\hline
\end{tabular}

Table 3. Multiplicator matrix elements for the FSDT theory - Scenario III: Face-face delamination.

\begin{tabular}{llllllllll}
\hline & Undelaminated & \multicolumn{3}{c}{ Delaminated } & \multicolumn{3}{c}{ Undelaminated } & \multicolumn{3}{c}{ Delaminated } \\
\cline { 2 - 9 }$[\mathrm{i}, \mathrm{j}]$ & $K_{i j}^{(0)}$ & $K_{i j}^{(1)}$ & $K_{i j}^{(0)}$ & $K_{i j}^{(1)}$ & {$[\mathrm{i}, \mathrm{j}]$} & $K_{i j}^{(0)}$ & $K_{i j}^{(1)}$ & $K_{i j}^{(0)}$ & $K_{i j}^{(1)}$ \\
\hline$[1,1]$ & $-\frac{1}{2} t_{1}$ & 1 & $-z_{R}^{(1)}$ & 1 & {$[3,1]$} & 0 & 0 & $-z_{R}^{(1)}+\frac{1}{2} t_{1}$ & 0 \\
{$[1,2]$} & $-z_{R}^{(2)}-\frac{1}{2} t_{2}$ & 0 & 0 & 0 & {$[3,2]$} & $-z_{R}^{(2)}+\frac{1}{2} t_{2}$ & 0 & $t_{2}$ & 0 \\
{$[1,3]$} & 0 & 0 & 0 & 0 & {$[3,3]$} & $\frac{1}{2} t_{3}$ & 1 & $\frac{1}{2} t_{3}$ & 1 \\
{$[1,4]$} & 0 & 0 & 0 & 0 & {$[3,4]$} & 0 & 0 & 1 & 0 \\
{$[2,1]$} & 0 & 0 & $-z_{R}^{(1)}+\frac{1}{2} t_{1}$ & 0 & {$[4,1]$} & 0 & 0 & 0 & 0 \\
{$[2,2]$} & $-z_{R}^{(2)}$ & 1 & $\frac{1}{2} t_{2}$ & 1 & {$[4,2]$} & $-z_{R}^{(2)}+\frac{1}{2} t_{2}$ & 0 & 0 & 0 \\
{$[2,3]$} & 0 & 0 & 0 & 0 & {$[4,3]$} & $t_{3}$ & 0 & 0 & 0 \\
{$[2,4]$} & 0 & 0 & 0 & 0 & {$[4,4]$} & $\frac{1}{4} t_{4}$ & 1 & $-z_{R}^{(4)}$ & 1 \\
\hline
\end{tabular}


Consequently, we eliminate $u_{0 i}$ and $v_{0 i}(i=1 \ldots 4)$ and $\phi_{(p) i}, i=1,3, p=x$ or $y$. The multiplicator matrix elements are collected in Tables 7 and 8 in Appendix 2.

Third-order plate theory. The third-order plate theory is applied to capture the mechanical behaviour of the core (ESLs 2 and 3 in Figure 1) only. Thus, ESLs 1 and 4 are modelled by second-order plate theories. The reason for this choice is the large model size that would result in case of a full TSDT model. The SEKC conditions are summarized in Table 1 (TSDT). The vector of primary parameters becomes:

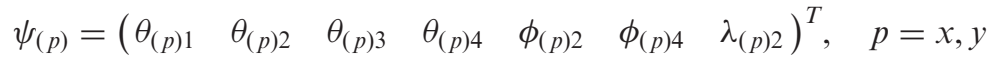

The parameters to be eliminated are $u_{0 i}$ and $v_{0 i}(i=1 \ldots 4)$ and $\phi_{(p) i}, i=1,3$ and $\lambda_{(p) 3}$ with $p=x$ or $y$. The multiplicator matrix elements are given in Appendix 3, Tables 12 and 13 .

\section{Delaminated part}

The delaminated region consists of a top and a bottom plate (refer to Figure 1). Each subplate is modelled by two further ESLs. The most essential difference between the delaminated and undelaminated plate regions is that in the delaminated region the in-plane displacements are not coupled at the delamination plane. Therefore, the global membrane displacements $u_{0}, v_{0}$ are replaced by $u_{0 b}, v_{0 b}$ for ESLs of the bottom plate, moreover by $u_{0 t}, v_{0 t}$ for the ESLs of the top plate in equation (7) in accordance with Figure 1:

$$
\begin{aligned}
& u_{(i)}=u_{0 b}+\left(K_{i j}^{(0)}+K_{i j}^{(1)} z^{(i)}+K_{i j}^{(2)}\left[z^{(i)}\right]^{2}+K_{i j}^{(3)}\left[z^{(i)}\right]^{3}\right) \psi_{(x) j}, \quad i=1 . .2, \\
& v_{(i)}=v_{0 b}+\left(K_{i j}^{(0)}+K_{i j}^{(1)} z^{(i)}+K_{i j}^{(2)}\left[z^{(i)}\right]^{2}+K_{i j}^{(3)}\left[z^{(i)}\right]^{3}\right) \psi_{(y) j}, \quad i=1 . .2 \\
& u_{(i)}=u_{0 t}+\left(K_{i j}^{(0)}+K_{i j}^{(1)} z^{(i)}+K_{i j}^{(2)}\left[z^{(i)}\right]^{2}+K_{i j}^{(3)}\left[z^{(i)}\right]^{3}\right) \psi_{(x) j}, \quad i=3 . .4, \\
& v_{(i)}=v_{0 t}+\left(K_{i j}^{(0)}+K_{i j}^{(1)} z^{(i)}+K_{i j}^{(2)}\left[z^{(i)}\right]^{2}+K_{i j}^{(3)}\left[z^{(i)}\right]^{3}\right) \psi_{(y) j}, \quad i=3 . .4
\end{aligned}
$$

where $j$ is a summation index, furthermore $w_{(i)}(x, y)=w(x, y)$ for every ESL.

First-order plate theory. For the FSDT model, the kinematic conditions imposed are:

$$
\begin{aligned}
\left.\left(u_{1}, v_{1}, w_{1}\right)\right|_{z^{(1)}=t_{1} / 2} & =\left.\left(u_{2}, v_{2}, w_{2}\right)\right|_{z^{(2)}=-t_{2} / 2}, \\
\left.\left(u_{3}, v_{3}, w_{3}\right)\right|_{z^{(2)}=t_{2} / 2} & =\left.\left(u_{3}, v_{3}, w_{3}\right)\right|_{z^{(3)}=-t_{3} / 2}, \\
\left.\left(u_{1}, v_{1}\right)\right|_{z^{(1)}=t_{2} / 2} & =\left(u_{0 b}(x, y), v_{0 b}(x, y)\right), \\
\left.\left(u_{3}, v_{3}\right)\right|_{z^{(3)}=t_{4} / 2} & =\left(u_{0 t}(x, y), v_{0 t}(x, y)\right)
\end{aligned}
$$


Table 4. The set of SEKC equations applied to FSDT, SSDT and TSDT - Delaminated part.

Equation (2) Equation (3) Equation (4) Equation (5) Equation (6)

\begin{tabular}{|c|c|c|c|c|c|}
\hline \multicolumn{6}{|c|}{ Scenario I } \\
\hline FSDT & $i=1, i=3$ & $\begin{array}{l}i=I, u_{0}=u_{0 b} \\
\quad \text { and } i=4, u_{0}=u_{0 t}\end{array}$ & - & - & - \\
\hline SSDT & $i=1, i=3$ & $\begin{array}{l}i=I, u_{0}=u_{0 b} \\
\quad \text { and } i=4, u_{0}=u_{0 t}\end{array}$ & - & - & $\begin{array}{l}\mathrm{I}=\mathrm{I}, \mathrm{m}=4 \\
\quad \text { and } \mathrm{I}=2, \mathrm{~m}=3\end{array}$ \\
\hline TSDT & $i=1, i=3$ & $\begin{array}{l}i=I, u_{0}=u_{0 b} \\
\quad \text { and } i=4, u_{0}=u_{0 t}\end{array}$ & $i=2$ & - & $\begin{array}{l}\mathrm{I}=\mathrm{I}, \mathrm{m}=4 \\
\quad \text { and } \mathrm{I}=2, \mathrm{~m}=3\end{array}$ \\
\hline \multicolumn{6}{|c|}{ Scenario II } \\
\hline FSDT & $i=1, i=3$ & $\begin{array}{l}i=I, u_{0}=u_{0 b} \\
\quad \text { and } i=4, u_{0}=u_{0 t}\end{array}$ & - & - & - \\
\hline SSDT & $i=1, i=3$ & $\begin{array}{l}i=I, u_{0}=u_{0 b} \\
\quad \text { and } i=4, u_{0}=u_{0 t}\end{array}$ & $i=3$ & - & $\mathrm{I}=\mathrm{I}, \mathrm{m}=4$ \\
\hline TSDT & $i=1, i=3$ & $\begin{array}{l}i=I, u_{0}=u_{0 b} \\
\quad \text { and } i=4, u_{0}=u_{0 t}\end{array}$ & $i=3$ & $i=3$ & $\mathrm{I}=\mathrm{I}, \mathrm{m}=4$ \\
\hline \multicolumn{6}{|c|}{ Scenario III } \\
\hline FSDT & $i=1, i=2$ & $\begin{array}{l}i=I, u_{0}=u_{0 b} \\
\quad \text { and } i=4, u_{0}=u_{0 t}\end{array}$ & - & - & - \\
\hline SSDT & $i=1, i=2$ & $\begin{array}{l}i=I, u_{0}=u_{0 b} \\
\quad \text { and } i=4, u_{0}=u_{0 t}\end{array}$ & - & - & $\begin{array}{l}\mathrm{I}=\mathrm{I}, \mathrm{m}=4 \\
\text { and } \mathrm{I}=3, \mathrm{~m}=4\end{array}$ \\
\hline TSDT & $i=1, i=2$ & $\begin{array}{l}i=I, u_{0}=u_{0 b} \\
\quad \text { and } i=4, u_{0}=u_{0 t}\end{array}$ & - & $i=3$ & $\begin{array}{l}\mathrm{I}=\mathrm{I}, \mathrm{m}=4 \\
\text { and } \mathrm{I}=3, \mathrm{~m}=4\end{array}$ \\
\hline
\end{tabular}

which are also summarized in Table 4 . Furthermore, the $K_{i j}$ constants are given in Tables 2 and 3, where $z_{R}^{(1)}$ and $z_{R}^{(4)}$ are the locations of the reference planes of top and bottom plates in the delaminated part (refer to Figure 1). It is important to note that a soft-core material is assumed, which has a very low modulus compared to that of the facesheets. In fact, the distances can be calculated based on the coupling stiffness matrix (B) [45] of the top (ESL3 + ESL4) and bottom (ESL1 + ESL2) plates. However, it is also a reasonable assumption that $z_{R}^{(1)}=z_{R}^{(4)}=0$. The vector of primary parameters is the same as that given by equation (9).

Second-order plate theory. The SEKC conditions applied for the SSDT model are collected in Table 4 for three different scenarios. In this case, the vector of primary parameters is given by equation (10). The multiplicator matrix elements obtained based on the SEKC conditions are collected in Tables 9 to 11 (Appendix 2).

Third-order plate theory. The third-order plate theory is applied to capture the mechanical behaviour of the core (ESLs 2 and 3 in Figure 1) only. Thus, ESLs 1 and 4 are modelled by second-order plate theories. The reason for this choice is the large model size that would result in case of a full TSDT model. The SEKC conditions 
are summarized in Table 4. For the core-core scenario, the vector of primary parameters becomes:

$$
\psi_{(p)}=\left(\begin{array}{llllllll}
\theta_{(p) 1} & \theta_{(p) 2} & \theta_{(p) 3} & \theta_{(p) 4} & \phi_{(p) 3} & \phi_{(p) 4} & \lambda_{(p) 2} & \left.\lambda_{(p) 3}\right)^{T}, \quad p=x, y
\end{array}\right.
$$

where the last element highlighted by the circle is the so-called autocontinuity (AC) parameter [105,106]. For the other two (face-core and face-face) scenarios, the vector of primary parameters takes the form of:

$$
\psi_{(p)}=\left(\begin{array}{lllllll}
\theta_{(p) 1} & \theta_{(p) 2} & \theta_{(p) 3} & \theta_{(p) 4} & \phi_{(p) 3} & \phi_{(p) 4} & \left.\lambda_{(p) 2}\right)^{T},
\end{array}, \quad p=x, y\right.
$$

The multiplicator matrix elements are given in Appendix 3 in Tables 14 to 16. On the basis of the displacement field, the governing equations are derived in the next section for each theory.

\section{Equilibrium equations}

Assuming small displacements and deformations in elastic structures, the strain field is obtained by [118]:

$$
\varepsilon_{i j}=\frac{1}{2}\left(u_{i, j}+u_{j, i}\right)
$$

The strains and shear strains in the sandwich plate are expressed as [45]:

$$
\left(\begin{array}{c}
\varepsilon_{x} \\
\varepsilon_{y} \\
\gamma_{x y}
\end{array}\right)_{(i)}=\left(\begin{array}{c}
\varepsilon_{x}^{(0)} \\
\varepsilon_{y}^{(0)} \\
\gamma_{x y}^{(0)}
\end{array}\right)_{(i)}+z^{(i)} \cdot\left(\begin{array}{c}
\varepsilon_{x}^{(1)} \\
\varepsilon_{y}^{(1)} \\
\gamma_{x y}^{(1)}
\end{array}\right)_{(i)}+\left[z^{(i)}\right]^{2} \cdot\left(\begin{array}{c}
\varepsilon_{x}^{(2)} \\
\varepsilon_{y}^{(2)} \\
\gamma_{x y}^{(2)}
\end{array}\right)_{(i)}+\left[z^{(i)}\right]^{3} \cdot\left(\begin{array}{c}
\varepsilon_{x}^{(3)} \\
\varepsilon_{y}^{(3)} \\
\gamma_{x y}^{(3)}
\end{array}\right)_{(i)}
$$

or $\{\varepsilon\}_{(i)}=\left\{\varepsilon^{(0)}\right\}_{(i)}+z^{(i)} \cdot\left\{\varepsilon^{(1)}\right\}_{(i)}+\left[z^{(i)}\right]^{2} \cdot\left\{\varepsilon^{(2)}\right\}_{(i)}+\left[z^{(i)}\right]^{3} \cdot\left\{\varepsilon^{(3)}\right\}_{(i)}$, which is third-order in terms of the through-thickness coordinate, $z^{(i)}$. The vector of transverse shear strains is:

$$
\left(\begin{array}{l}
\gamma_{x z} \\
\gamma_{y z}
\end{array}\right)_{(i)}=\left(\begin{array}{l}
\gamma_{x z}^{(0)} \\
\gamma_{y z}^{(0)}
\end{array}\right)_{(i)}+z^{(i)} \cdot\left(\begin{array}{c}
\gamma_{x z}^{(1)} \\
\gamma_{y z}^{(1)}
\end{array}\right)_{(i)}+\left[z^{(i)}\right]^{2} \cdot\left(\begin{array}{l}
\gamma_{x z}^{(2)} \\
\gamma_{y z}^{(2)}
\end{array}\right)_{(i)}
$$

or in a compact form: $\{\gamma\}_{(i)}=\left\{\gamma^{(0)}\right\}_{(i)}+z^{(i)} \cdot\left\{\gamma^{(1)}\right\}_{(i)}+\left[z^{(i)}\right]^{2} \cdot\left\{\gamma^{(2)}\right\}_{(i)}$, which is second-order in terms of $z^{(i)}$. By using the material law and calculating the stresses, then by the integration of the stresses over the thickness yields the stress resultants. 
In vector form, we have [45]:

$$
\left(\begin{array}{c}
N_{\alpha \beta} \\
M_{\alpha \beta} \\
L_{\alpha \beta} \\
P_{\alpha \beta}
\end{array}\right)_{(i)}=\int_{-t_{i} / 2}^{t_{i} / 2} \sigma_{\alpha \beta}\left(\begin{array}{c}
1 \\
z \\
z^{2} \\
z^{3}
\end{array}\right)_{(i)} d z^{(i)},\left(\begin{array}{c}
Q_{\alpha} \\
R_{\alpha} \\
S_{\alpha}
\end{array}\right)_{(i)}=\int_{-t_{i} / 2}^{t_{i} / 2} \tau_{\alpha z}\left(\begin{array}{c}
1 \\
z \\
z^{2}
\end{array}\right)_{(i)} d z^{(i)}
$$

where $\alpha$ and $\beta$ take $x$ or $y$. The relationship between the strain field and the stress resultants can be determined by substituting back equations (18) and (19) into (20) and by considering the orthotropic material law under plane stress assumption [117]. This results in the following [104]:

$$
\begin{gathered}
\left(\begin{array}{c}
\{N\} \\
\{M\} \\
\{L\} \\
\{P\}
\end{array}\right)_{(i)}=\left[\begin{array}{llll}
{[A]} & {[B]} & {[D]} & {[E]} \\
{[B]} & {[D]} & {[E]} & {[F]} \\
{[D]} & {[E]} & {[F]} & {[G]} \\
{[E]} & {[F]} & {[G]} & {[H]}
\end{array}\right]_{(i)}\left(\begin{array}{c}
\left\{\varepsilon^{(0)}\right\} \\
\left\{\varepsilon^{(1)}\right\} \\
\left\{\varepsilon^{(2)}\right\} \\
\left\{\varepsilon^{(3)}\right\}
\end{array}\right)_{(i)} \\
\left(\begin{array}{c}
\{Q\} \\
\{R\} \\
\{S\}
\end{array}\right)_{(i)}=\left[\begin{array}{lll}
{[A]} & {[B]} & {[D]} \\
{[B]} & {[D]} & {[E]} \\
{[D]} & {[E]} & {[F]}
\end{array}\right]_{(i)}\left(\begin{array}{l}
\left\{\gamma^{(0)}\right\} \\
\left\{\gamma^{(1)}\right\} \\
\left\{\gamma^{(2)}\right\}
\end{array}\right)_{(i)}
\end{gathered}
$$

where $\{N\}_{(i)}^{\mathrm{T}}=\left\{\begin{array}{lll}N_{x} & N_{y} & \left.N_{x y}\right\}_{(i)}\end{array}\right.$ is the vector of in-plane plate forces, $\{M\}_{(i)}^{\mathrm{T}}=$ $\left\{\begin{array}{lll}M_{x} & M_{y} & M_{x y}\end{array}\right\}_{(i)}$ is the vector of bending and twisting moments,

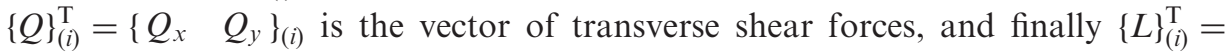
$\left\{\begin{array}{lll}L_{x} & L_{y} & L_{x y}\end{array}\right\}_{(i)}, \quad\{P\}_{(i)}^{\mathrm{T}}=\left\{\begin{array}{llll}P_{x} & P_{y} & P_{x y}\end{array}\right\}_{(i)} \quad$ and $\quad\{R\}_{(i)}^{\mathrm{T}}=\left\{\begin{array}{ll}R_{x} & R_{y}\end{array}\right\}_{(i)}, \quad\{S\}_{(i)}^{\mathrm{T}}=$ $\left\{\begin{array}{ll}S_{x} & S_{y}\end{array}\right\}_{(i)}$ are the vectors of higher-order stress resultants. In equations (21) and (22), $A_{p q}$ is the extensional, $B_{p q}$ is coupling, $D_{p q}$ is the bending, $E_{p q}, F_{p q}, G_{p q}$ and $H_{p q}$ are higher-order stiffnesses defined as [104]:

$$
\left(A_{p q}, B_{p q}, D_{p q}, E_{p q}, F_{p q}, G_{p q}, H_{p q}\right)_{(i)}=\sum_{m=1}^{N_{l(i)}} \int_{z_{m}^{(i)}}^{z_{m+1}^{(i)}} \bar{C}_{p q}^{(m)}\left(1, z, z^{2}, z^{3}, z^{4}, z^{5}, z^{6}\right)^{(i)} \mathrm{d} z^{(i)}
$$

where $N_{l(i)}$ is the number of layers in the $i$ th ESL. The stiffnesses above have to be calculated with respect to the local reference planes (midplanes) for each ESL. To derive the equilibrium equations of the plate system in a compact and invariant 
form, we define the following vectors:

$$
\begin{aligned}
\mathbf{N}_{i}^{(x, x y)} & =\left(\begin{array}{ll}
N_{x} & N_{x y}
\end{array}\right)_{(i)}^{T}, \quad \mathbf{N}_{i}^{(x y, y)}=\left(\begin{array}{ll}
N_{x y} & N_{y}
\end{array}\right)_{(i)}^{T}, \\
\mathbf{M}_{i}^{(x, x y)} & =\left(\begin{array}{lll}
M_{x} & M_{x y}
\end{array}\right)_{(i)}^{T}, \quad \mathbf{M}_{i}^{(x y, y)}=\left(\begin{array}{ll}
M_{x y} & M_{y}
\end{array}\right)_{(i)}^{T}
\end{aligned}
$$

The vectors of higher-order stress resultants become:

$$
\begin{array}{ll}
\mathbf{L}_{i}^{(x, x y)}=\left(\begin{array}{ll}
L_{x} & L_{x y}
\end{array}\right)_{(i)}^{T}, \quad \mathbf{L}_{i}^{(x y, y)}=\left(\begin{array}{ll}
L_{x y} & L_{y}
\end{array}\right)_{(i)}^{T}, \\
\mathbf{P}_{i}^{(x, x y)}=\left(\begin{array}{lll}
P_{x} & P_{x y}
\end{array}\right)_{(i)}^{T}, & \mathbf{P}_{i}^{(x y, y)}=\left(\begin{array}{ll}
P_{x y} & P_{y}
\end{array}\right)_{(i)}^{T}
\end{array}
$$

Finally, the vectors of shear and higher-order forces become:

$$
\mathbf{Q}_{i}=\left(\begin{array}{ll}
Q_{x} & Q_{y}
\end{array}\right)_{(i)}^{T}, \quad \mathbf{R}_{i}=\left(\begin{array}{ll}
R_{x} & R_{y}
\end{array}\right)_{(i)}^{T}, \quad \mathbf{S}_{i}=\left(\begin{array}{ll}
S_{x} & S_{y}
\end{array}\right)_{(i)}^{T}
$$

In the sequel, the equilibrium equations are derived separately for the undelaminated and delaminated regions.

\section{Undelaminated region}

By formulating the total potential energy of the system [117] and setting the sum of coefficients for the virtual membrane displacements $\left(\delta u_{0}, \delta v_{0}\right)$, primary parameters $\left(\delta \psi_{(x) j}, \delta \psi_{(y) j}\right)$ and the deflection $(\delta w)$ to zero leads to three sets of equations. The equilibrium of the in-plane forces involves the equations below independently of the applied theory (FSDT, SSDT or TSDT):

$$
\delta u_{0}: \quad \sum_{i=1}^{4} \nabla \cdot \mathbf{N}_{i}^{(x, x y)}=0, \quad \delta v_{0}: \quad \sum_{i=1}^{4} \nabla \cdot \mathbf{N}_{i}^{(x y, x)}=0
$$

where $\nabla=\frac{\partial}{\partial x} \mathbf{i}+\frac{\partial}{\partial v} \mathbf{j}$ is the Hamilton differential operator [118]. In the general sense (using FSDT, SSDT or TSDT), the number of primary parameters (ignoring the global membrane displacements) in the displacement field is $r$, which is equal to the number of elements in $\psi_{(p)}$ and $j=1 \ldots r$. By collecting the coefficients of the virtual primary displacement parameters in the expression of the total potential energy and equating the result to zero, we have the following equations:

$$
\begin{aligned}
\delta \psi_{(x) j}: & \left\{\psi_{i=1}^{4} K_{i j}^{(0)}\left(\begin{array}{c}
\nabla \cdot \mathbf{N}_{i}^{(x, x y)} \\
\nabla \cdot \mathbf{N}_{i}^{(x y, y)}
\end{array}\right)+K_{i j}^{(1)}\left(\begin{array}{c}
\nabla \cdot \mathbf{M}_{i}^{(x, x y)} \\
\nabla \cdot \mathbf{M}_{i}^{(x y, y)}
\end{array}\right)+K_{i j}^{(2)}\left(\begin{array}{c}
\nabla \cdot \mathbf{L}_{i}^{(x, x y)} \\
\nabla \cdot \mathbf{L}_{i}^{(x y, y)}
\end{array}\right)\right. \\
& +K_{i j}^{(3)}\left(\begin{array}{c}
\nabla \cdot \mathbf{P}_{i}^{(x, x y)} \\
\nabla \cdot \mathbf{P}_{i}^{(x y, y)}
\end{array}\right)-K_{i j}^{(1)}\left(\begin{array}{c}
Q_{x(i)} \\
Q_{y(i)}
\end{array}\right)-2 K_{i j}^{(2)}\left(\begin{array}{c}
R_{x(i)} \\
R_{y(i)}
\end{array}\right)-3 K_{i j}^{(3)}\left(\begin{array}{c}
S_{x(i)} \\
S_{y(i)}
\end{array}\right)=\left(\begin{array}{l}
0 \\
0
\end{array}\right)
\end{aligned}
$$


where $\psi_{(x) j}$ and $\psi_{(y) j}$ denote the primary parameters. By collecting the coefficients of the $\delta w(x, y)$, plate deflection in the total potential energy and setting their sum to zero leads to:

$$
\delta w: \quad \sum_{i=1}^{4} \nabla \cdot \mathbf{Q}_{i}+q=0
$$

where $q$ is the external surface load, moreover $\mathbf{Q}$ is the vector of shear forces (refer to equation (26)). Equations (27) to (29) define the invariant form of the equilibrium equations, because independently of the applied theory, these equations have the same form. It is apparent that the differences among the equilibrium equations of FSDT, SSDT and TSDT are the $K_{i j}$ displacement multiplicator matrix elements and the $\psi_{(p)}$ vector of primary parameters.

\section{Delaminated region}

Using the principle of virtual work, it is possible to determine the equilibrium equations of the delaminated part as well. Thus, the equilibrium equations of inplane forces take the form below:

$$
\begin{aligned}
& \delta u_{0 b}: \quad \sum_{i=1}^{2} \nabla \cdot \mathbf{N}_{i}^{(x, x y)}=0, \quad \delta u_{0 t}: \quad \sum_{i=3}^{4} \nabla \cdot \mathbf{N}_{i}^{(x, x y)}=0, \\
& \delta v_{0 b}: \quad \sum_{i=1}^{2} \nabla \cdot \mathbf{N}_{i}^{(x y, x)}=0, \quad \delta v_{0 t}: \quad \sum_{i=3}^{4} \nabla \cdot \mathbf{N}_{i}^{(x y, x)}=0
\end{aligned}
$$

The form of the other equilibrium equations is the same as those given by equations (28) and (29).

Finally, it should be noted that the fundamental solutions of Linear Elastic Fracture Mechanics (LEFM) are singular for problems including cracks $[119,120]$. On the contrary, equation (7) and equations (12) and (13) do not contain any singular terms, thus the solutions in this work are essentially nonsingular for all of the mechanical fields.

\section{Simply supported sandwich plate}

As an example, a simply supported delaminated plate is considered as shown by Figure 2. The plate is loaded by a uniformly distributed load, denoted by $Q_{0}$. The plate contains a through-width delamination with length, $a$, the length of the undelaminated part is $c$. Moreover, $t_{t}=t_{1}+t_{2}, t_{b}=t_{3}+t_{4}$, respectively. In accordance with the Lévy type solution [47,121], the parameters of the 


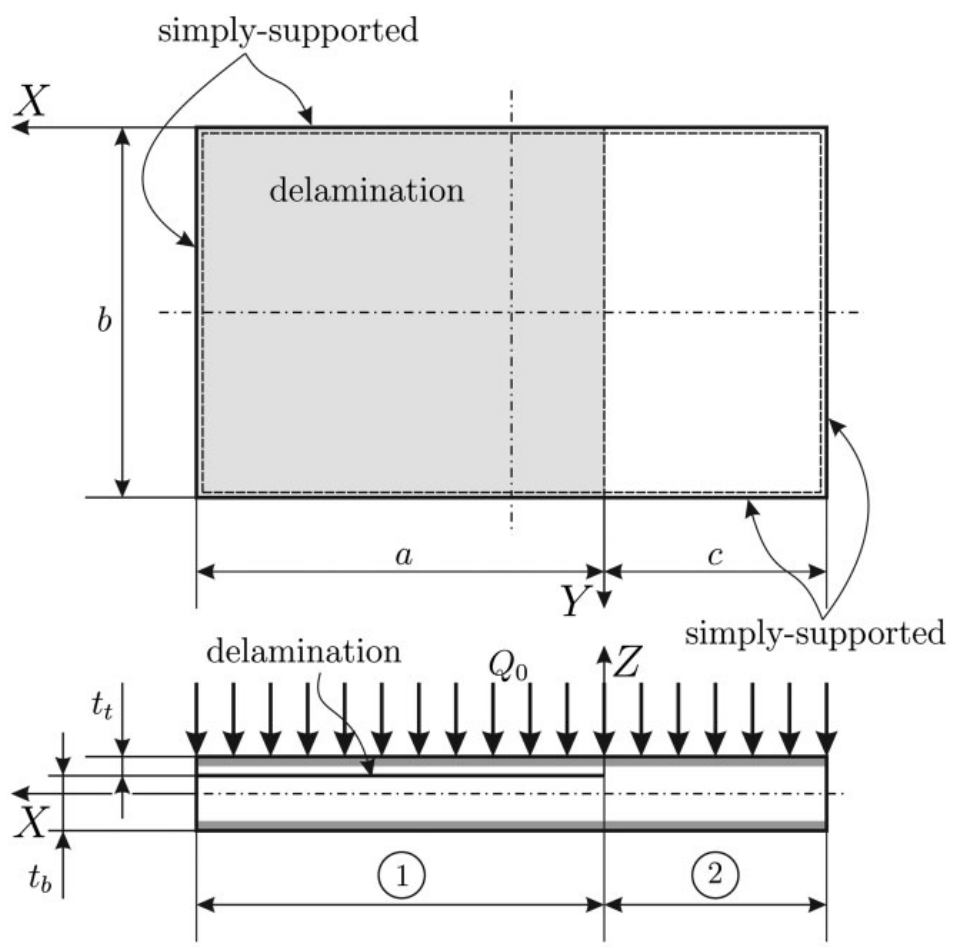

Figure 2. Simply supported delaminated sandwich plate with uniformly distributed load.

displacement field of simply supported plates are formulated as:

$$
\left\{\begin{array}{l}
\psi_{(x) i}(x, y) \\
\psi_{(y) i}(x, y)
\end{array}\right\}=\sum_{n=1}^{\infty}\left\{\begin{array}{c}
\Phi_{(x) i n}(x) \sin \beta y \\
\Phi_{(y) i n}(x) \cos \beta y
\end{array}\right\},\left\{\begin{array}{c}
u(x, y) \\
v(x, y) \\
q(x, y) \\
w(x, y)
\end{array}\right\}=\sum_{n=1}^{\infty}\left\{\begin{array}{c}
U_{n}(x) \sin \beta y \\
V_{n}(x) \cos \beta y \\
Q_{n}(x) \sin \beta y \\
W_{n}(x) \sin \beta y
\end{array}\right\}
$$

It is important to note that Lévy type solution implies that the $u$ displacement component vanishes at the $y=0$ and $y=b$ edges of the plate. Considering the parameters in equation (31), the trial functions for any ESL in the plate including the undelaminated and delaminated portions are:

$$
\left\{\begin{array}{c}
\theta_{(x)}(x, y) \\
\theta_{(y)}(x, y) \\
\phi_{(x)}(x, y) \\
\phi_{(y)}(x, y) \\
\lambda_{(x)}(x, y) \\
\lambda_{(y)}(x, y)
\end{array}\right\}=\sum_{n=1}^{\infty}\left\{\begin{array}{c}
X_{n}(x) \sin \beta y \\
Y_{n}(x) \cos \beta y \\
T_{x n}(x) \sin \beta y \\
T_{y n}(x) \cos \beta y \\
Z_{x n}(x) \sin \beta y \\
Z_{y n}(x) \cos \beta y
\end{array}\right\},\left\{\begin{array}{c}
u_{0}(x, y) \\
v_{0}(x, y) \\
u_{0 \delta}(x, y) \\
v_{0 \delta}(x, y) \\
q(x, y) \\
w(x, y)
\end{array}\right\}=\sum_{n=1}^{\infty}\left\{\begin{array}{c}
U_{0 n}(x) \sin \beta y \\
V_{0 n}(x) \cos \beta y \\
U_{0 \delta n}(x) \sin \beta y \\
V_{0 \delta n}(x) \cos \beta y \\
Q_{n}(x) \sin \beta y \\
W_{n}(x) \sin \beta y
\end{array}\right\}
$$


Table 5. State vector elements for FSDT and SSDT theories.

\begin{tabular}{|c|c|c|c|c|}
\hline \multirow[b]{2}{*}{ Scenario } & \multicolumn{2}{|l|}{ FSDT } & \multicolumn{2}{|l|}{ SSDT } \\
\hline & $\begin{array}{l}\text { Undelaminated } \\
\text { (22) }\end{array}$ & $\begin{array}{l}\text { Delaminated } \\
(26)\end{array}$ & $\begin{array}{l}\text { Undelaminated } \\
(30)\end{array}$ & $\begin{array}{l}\text { Delaminated } \\
\text { (34) }\end{array}$ \\
\hline \multirow[t]{9}{*}{ I, II, III } & $U_{0}, U_{0}^{\prime}, V_{0}, V_{0}^{\prime}$ & $U_{0 b}, U_{0 b}^{\prime}, V_{0 b}, V_{0 b}^{\prime}$, & $U_{0 b}, U_{0 b}^{\prime}, V_{0 b}, V_{0 b}^{\prime}$ & $U_{0 b}, U_{0 b}^{\prime}, V_{0 b}, V_{0 b}^{\prime}$, \\
\hline & $X_{n 1}, X_{n 1}^{\prime}, Y_{n 1}, Y_{n 1}^{\prime}$ & $X_{n 1}, X_{n 1}^{\prime}, Y_{n 1}, Y_{n 1}^{\prime}$, & $X_{n 1}, X_{n 1}^{\prime}, Y_{n 1}, Y_{n \mid}^{\prime}$ & $X_{n 1}, X_{n 1}^{\prime}, Y_{n 1}, Y_{n 1}^{\prime}$, \\
\hline & $X_{n 2}, X_{n 2}^{\prime}, Y_{n 2}, Y_{n 2}^{\prime}$ & $X_{n 2}, X_{n 2}^{\prime}, Y_{n 2}, Y_{n 2}^{\prime}$, & $X_{n 2}, X_{n 2}^{\prime}, Y_{n 2}, Y_{n 2}^{\prime}$ & $X_{n 2}, X_{n 2}^{\prime}, Y_{n 2}, Y_{n 2}^{\prime}$, \\
\hline & $X_{n 3}, X_{n 3}^{\prime}, Y_{n 3}, Y_{n 3}^{\prime}$, & $U_{0 t}, U_{0 t}^{\prime}, V_{0 t}, V_{0 t}^{\prime}$, & $X_{n 3}, X_{n 3}^{\prime}, Y_{n 3}, Y_{n 3}^{\prime}$ & $U_{0 t}, U_{0 t}^{\prime}, V_{0 t}, V_{0 t}^{\prime}$ \\
\hline & $X_{n 4}, X_{n 4}^{\prime}, Y_{n 4}, Y_{n 4}^{\prime}$ & $X_{n 3}, X_{n 3}^{\prime}, Y_{n 3}, Y_{n 3}^{\prime}$, & $X_{n 4}, X_{n 4}^{\prime}, Y_{n 4}, Y_{n 4}^{\prime}$ & $X_{n 3}, X_{n 3}^{\prime}, Y_{n 3}, Y_{n 3}^{\prime}$, \\
\hline & $W_{n}, W_{n}^{\prime}$ & $X_{n 4}, X_{n 4}^{\prime}, Y_{n 4}, Y_{n 4}^{\prime}$, & $T_{x n 2}, T_{x n 2}^{\prime}, T_{y n 2}, T_{y n 2}^{\prime}$, & $X_{n 4}, X_{n 4}^{\prime}, Y_{n 4}, Y_{n 4}^{\prime}$ \\
\hline & & $W_{n}, W_{n}^{\prime}$ & $T_{x n 4}, T_{x n 4}^{\prime}, T_{y n 4}, T_{y n 4}^{\prime}$, & $T_{x n 2}, T_{x n 2}^{\prime}, T_{y n 2}, T_{y n 2}^{\prime}$, \\
\hline & & & $W_{n}, W_{n}^{\prime}$ & $T_{x n 4}, T_{x n 4}^{\prime}, T_{y n 4}, T_{y n 4}^{\prime}$, \\
\hline & & & & $W_{n}, W_{n}^{\prime}$ \\
\hline
\end{tabular}

where $\beta=n \pi / b, b$ is the plate width and $\delta=t$ for the top plate, $\delta=b$ for the bottom plate, respectively. The function of the external load in this case is $Q_{n}=4 Q_{0} /(n \pi)$ [117]. By taking back the solution in equation (32) into the strain field (equations (18) and (19)), then by expressing the stress resultants in accordance with equations (21) and (22), we can utilize the equilibrium equations given by equations (27) to (30) to reduce the system of Partial Differential Equations (PDEs) to a system of Ordinary Differential Equations (ODEs), which can be solved by the state-space approach [122]:

$$
\mathbf{Z}^{\prime}=\mathbf{T Z}+\mathbf{F}
$$

The state vector $\mathbf{Z}$ of the undelaminated part contains the elements in accordance with Tables 5 (FSDT and SSDT) and 6 (TSDT). In the parentheses, the number of elements is indicated equalling the size of the system matrix, $\mathbf{T}$ in equation (33). Moreover, $\mathbf{F}$ is the vector external load. The system matrix $\mathbf{T}$ is a constant matrix, the components are not given here, but similar problems have been solved and detailed, e.g. in $[102,104]$. The general solution of equation (33) is [123]:

$$
\mathbf{Z}(x)=e^{\mathbf{T} x}\left(\mathbf{K}+\int_{x_{0}}^{x} e^{-\mathbf{T} \xi} \mathbf{F}(\xi) \mathrm{d} \xi\right)=\mathbf{G}(x) \mathbf{K}+\mathbf{H}(x)
$$

where $\mathbf{K}$ is the vector of unknown constants of the solution functions [117]. The state-space models of the undelaminated and delaminated regions have to 
Table 6. State vector elements for TSDT theories.

\begin{tabular}{|c|c|c|c|c|}
\hline & \multicolumn{2}{|l|}{ Scenario I } & \multicolumn{2}{|l|}{ Scenarios II and III } \\
\hline & $\begin{array}{l}\text { Undelaminated } \\
\text { (34) }\end{array}$ & $\begin{array}{l}\text { Delaminated } \\
(42)\end{array}$ & $\begin{array}{l}\text { Undelaminated } \\
\text { (34) }\end{array}$ & $\begin{array}{l}\text { Delaminated } \\
\text { (38) }\end{array}$ \\
\hline \multirow[t]{11}{*}{ TSDT } & $\mathrm{U}_{0}, U_{0}^{\prime}, \mathrm{V}_{0}, V_{0}^{\prime}$ & $U_{0 b}, U_{0 b}^{\prime}, V_{0 b}, V_{0 b}^{\prime}$ & $U_{0 b}, U_{0 b}^{\prime}, V_{0 b}, V_{0 b}^{\prime}$ & $U_{0 b}, U_{0 b}^{\prime}, V_{0 b}, V_{0 b}^{\prime}$ \\
\hline & $X_{n 1}, X_{n 1}^{\prime}, Y_{n 1}, Y_{n \mid}^{\prime}$ & $X_{n 1}, X_{n 1}^{\prime}, Y_{n 1}, Y_{n \mid}^{\prime}$ & $X_{n 1}, X_{n \mid}^{\prime}, Y_{n 1}, Y_{n \mid}^{\prime}$ & $X_{n 1}, X_{n 1}^{\prime}, Y_{n 1}, Y_{n 1}^{\prime}$ \\
\hline & $X_{n 2}, X_{n 2}^{\prime}, Y_{n 2}, Y_{n 2}^{\prime}$ & $X_{n 2}, X_{n 2}^{\prime}, Y_{n 2}, Y_{n 2}^{\prime}$ & $X_{n 2}, X_{n 2}^{\prime}, Y_{n 2}, Y_{n 2}^{\prime}$ & $X_{n 2}, X_{n 2}^{\prime}, Y_{n 2}, Y_{n 2}^{\prime}$ \\
\hline & $X_{n 3}, X_{n 3}^{\prime}, Y_{n 3}, Y_{n 3}^{\prime}$ & $U_{0 t}, U_{0 t}^{\prime}, V_{0 t}, V_{0 t}^{\prime}$ & $X_{n 3}, X_{n 3}^{\prime}, Y_{n 3}, Y_{n 3}^{\prime}$ & $U_{0 t}, U_{0 t}^{\prime}, V_{0 t}, V_{0 t}^{\prime}$ \\
\hline & $X_{n 4}, X_{n 4}^{\prime}, Y_{n 4}, Y_{n 4}^{\prime}$ & $X_{n 3}, X_{n 3}^{\prime}, Y_{n 3}, Y_{n 3}^{\prime}$ & $X_{n 4}, X_{n 4}^{\prime}, Y_{n 4}, Y_{n 4}^{\prime}$ & $X_{n 3}, X_{n 3}^{\prime}, Y_{n 3}, Y_{n 3}^{\prime}$, \\
\hline & $T_{x n 2}, T_{x n 2}^{\prime}, T_{y n 2}, T_{y n 2}^{\prime}$ & $X_{n 4}, X_{n 4}^{\prime}, Y_{n 4}, Y_{n 4}^{\prime}$ & $T_{x n 2}, T_{x n 2}^{\prime}, T_{y n 2}, T_{y n 2}^{\prime}$ & $X_{n 4}, X_{n 4}^{\prime}, Y_{n 4}, Y_{n 4}^{\prime}$ \\
\hline & $T_{x n 4}, T_{x n 4}^{\prime}, T_{y n 4}, T_{y n 4}^{\prime}$ & $T_{x n 2}, T_{x n 2}^{\prime}, T_{y n 2}, T_{y n 2}^{\prime}$ & $T_{x n 4}, T_{x n 4}^{\prime}, T_{y n 4}, T_{y n 4}^{\prime}$ & $T_{x n 2}, T_{x n 2}^{\prime}, T_{y n 2}, T_{y n 2}^{\prime}$ \\
\hline & $Z_{x n 2}, Z_{x n 2}^{\prime}, Z_{y n 2}, Z_{y n 2}^{\prime}$, & $T_{x n 4}, T_{x n 4}^{\prime}, T_{y n 4}, T_{y n 4}^{\prime}$ & $Z_{x n 2}, Z_{x n 2}^{\prime}, Z_{y n 2}, Z_{y n 2}^{\prime}$ & $T_{x n 2}, T_{x n 2}^{\prime}, T_{y n 2}, T_{y n 2}^{\prime}$ \\
\hline & $W_{n}, W_{n}^{\prime}$ & $Z_{x n 2}, Z_{x n 2}^{\prime}, Z_{y n 2}, Z_{y n 2}^{\prime}$ & $W_{n}, W_{n}^{\prime}$ & $Z_{x n 2}, Z_{x n 2}^{\prime}, Z_{y n 2}, Z_{y n 2}^{\prime}$, \\
\hline & & $Z_{x n 3}, Z_{x n 3}^{\prime}, Z_{y n 3}, Z_{y n 3}^{\prime}$ & & $W_{n}, W_{n}^{\prime}$ \\
\hline & & $W_{n}, W_{n}^{\prime}$ & & \\
\hline
\end{tabular}

be created separately, then the continuity of displacements and stress resultants have to be ensured. These are detailed in the next subsection.

\section{Boundary and continuity conditions}

The boundary conditions of the problem in Figure 2 with respect to the displacement parameters are detailed below with respect to the applied theory and depending on the scenario. For the delaminated region, we have:

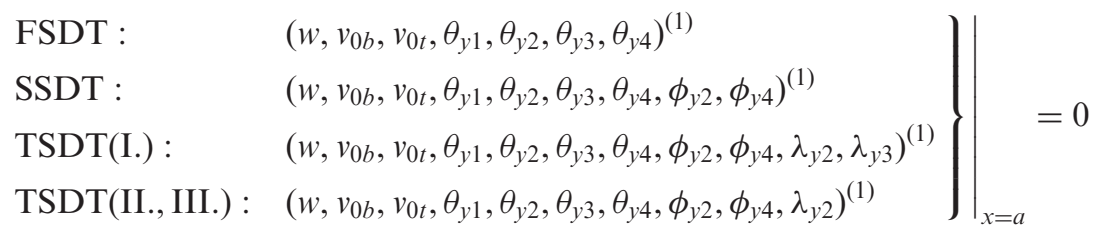

For the undelaminated region, the following conditions are imposed:

$$
\left.\begin{array}{ll}
\text { FSDT : } & \left(w, v_{0}, \theta_{y 1}, \theta_{y 2}, \theta_{y 3}, \theta_{y 4}\right)^{(2)} \\
\text { SSDT : } & \left(w, v_{0}, \theta_{y 1}, \theta_{y 2}, \theta_{y 3}, \theta_{y 4}, \phi_{y 2}, \phi_{y 4}\right)^{(2)} \\
\text { TSDT : } & \left(w, v_{0}, \theta_{y 1}, \theta_{y 2}, \theta_{y 3}, \theta_{y 4}, \phi_{y 2}, \phi_{y 4}, \lambda_{y 2}\right)^{(2)}
\end{array}\right\}\left.\right|_{x=-c}=0
$$


For the stress resultants, the imposed conditions are:

$$
\left.\begin{array}{lll}
\text { FSDT(I., II.) : } & \left(N_{x 1}+N_{x 2}, N_{x 3}+N_{x 4}, M_{x 1}, M_{x 2}, M_{x 3}, M_{x 4}\right)^{(1)} \\
\operatorname{FSDT}(\mathrm{III} .): & \left(N_{x 1}+N_{x 2}+N_{x 3}, N_{x 4}, M_{x 1}, M_{x 2}, M_{x 3}, M_{x 4}\right)^{(1)}
\end{array}\right\}\left.\right|_{x=a}=0
$$

for the FSDT solution, moreover:

$$
\begin{array}{ll}
\operatorname{SSDT}(\text { I., II. }): & \left(N_{x 1}+N_{x 2}, N_{x 3}+N_{x 4}, M_{x 1}, M_{x 2}, M_{x 3}, M_{x 4}, L_{x 2}, L_{x 4}\right)^{(1)} \\
\operatorname{SSDT}(\mathrm{III} .): & \left(N_{x 1}+N_{x 2}+N_{x 3}, N_{x 4}, M_{x 1}, M_{x 2}, M_{x 3}, M_{x 4}, L_{x 2}, L_{x 4}\right)^{(1)}
\end{array}||_{x=a}=0
$$

in the case of the SSDT solution, and finally:

$$
\left.\begin{array}{lll}
\text { TSDT(I.) : } & \left(N_{x 1}+N_{x 2}, N_{x 3}+N_{x 4}, M_{x 1}, M_{x 2}, M_{x 3}, M_{x 4}, L_{x 2}, L_{x 4}, P_{x 2}, P_{x 3}\right)^{(1)} \\
\text { TSDT(II.) : } & \left(N_{x 1}+N_{x 2}, N_{x 3}+N_{x 4}, M_{x 1}, M_{x 2}, M_{x 3}, M_{x 4}, L_{x 2}, L_{x 4}, P_{x 2}\right)^{(1)} \\
\operatorname{TSDT}(\text { III. }): & \left(N_{x 1}+N_{x 2}+N_{x 3}, N_{x 4}, M_{x 1}, M_{x 2}, M_{x 3}, M_{x 4}, L_{x 2}, L_{x 4}, P_{x 2}\right)^{(1)}
\end{array}\right\}\left.\right|_{x=a}=0
$$

in the case of the TSDT solution. The undelaminated region involves the following boundary conditions:

$$
\left.\begin{array}{ll}
\text { FSDT : } & \left(N_{x 1}+N_{x 2}+N_{x 3}+N_{x 4}, M_{x 1}, M_{x 2}, M_{x 3}, M_{x 4}\right)^{(2)} \\
\text { SSDT }: & \left(N_{x 1}+N_{x 2}+N_{x 3}+N_{x 4}, M_{x 1}, M_{x 2}, M_{x 3}, M_{x 4}, L_{x 2}, L_{x 4}\right)^{(2)} \\
\text { TSDT }: & \left(N_{x 1}+N_{x 2}+N_{x 3}+N_{x 4}, M_{x 1}, M_{x 2}, M_{x 3}, M_{x 4}, L_{x 2}, L_{x 4}, P_{x 2}\right)^{(2)}
\end{array}\right\}\left.\right|_{x=-c}=0
$$

The continuity conditions are formulated against the displacement parameters and the stress resultants. The continuity conditions of the membrane displacements should be imposed for ESL1 and ESL4 (or alternatively ESL2 and ESL3):

$$
\begin{aligned}
& \left(\begin{array}{c}
u_{0 b} \\
v_{0 b}
\end{array}\right)+\left.\sum_{j=1 . . q_{l}} K_{1 j}^{(0)}\left(\begin{array}{c}
\psi_{(x) j} \\
\psi_{(y) j}
\end{array}\right)\right|_{x=+0} ^{(1)}=\left(\begin{array}{c}
u_{0} \\
v_{0}
\end{array}\right)+\left.\sum_{j=1 \ldots q_{l}} K_{1 j}^{(0)}\left(\begin{array}{c}
\psi_{(x) j} \\
\psi_{(y) j}
\end{array}\right)\right|_{x=-0} ^{(2)}, \\
& \left(\begin{array}{c}
u_{0 t} \\
v_{0 t}
\end{array}\right)+\left.\sum_{j=1 . . q_{l}} K_{4 j}^{(0)}\left(\begin{array}{c}
\psi_{(x) j} \\
\psi_{(y) j}
\end{array}\right)\right|_{x=+0} ^{(1)}=\left(\begin{array}{c}
u_{0} \\
v_{0}
\end{array}\right)+\left.\sum_{j=1 . . q_{l}} K_{4 j}^{(0)}\left(\begin{array}{c}
\psi_{(x) j}^{*} \\
\psi_{(y) j}^{*}
\end{array}\right)\right|_{x=-0} ^{(2)}
\end{aligned}
$$

where $q_{l}$ is the number of primary parameters in equations (9) to (11) and (15) and (16) depending on the theory and scenario. For the other conditions, we define the 
set of parameters below:

$$
g_{\alpha}= \begin{cases}\left(w, w^{\prime}, \theta_{x 1}, \theta_{y 1}, \theta_{x 2}, \theta_{y 2}, \theta_{x 3}, \theta_{y 3}, \theta_{x 4}, \theta_{y 4}\right) & : \text { FSDT }, \\ \left(w, w^{\prime}, \theta_{x 1}, \theta_{y 1}, \theta_{x 2}, \theta_{y 2}, \theta_{x 3}, \theta_{y 3}, \theta_{x 4}, \theta_{y 4}, \phi_{x 2}, \phi_{y 2}, \phi_{x 4}, \phi_{y 4}\right) & : \text { SSDT, } \\ \left(w, w^{\prime}, \theta_{x 1}, \theta_{y 1}, \theta_{x 2}, \theta_{y 2}, \theta_{x 3}, \theta_{y 3}, \theta_{x 4}, \theta_{y 4}, \phi_{x 2}, \phi_{y 2}, \phi_{x 4}, \phi_{y 4}, \lambda_{x 2}, \lambda_{y 2}\right) & : \text { TSDT } .\end{cases}
$$

The following condition should then be satisfied:

$$
\left.g_{\alpha}^{(1)}\right|_{x=+0}=\left.g_{\alpha}^{(2)}\right|_{x=-0}
$$

In accordance with equations (27), (28) and (30), the sum of the membrane forces and the equivalent stress resultants should be continuous between regions 1 and 2 . The equivalent bending and twisting moments are defined as:

$$
\begin{aligned}
\left(\begin{array}{c}
\hat{M}_{x i} \\
\hat{M}_{x y i}
\end{array}\right)= & \left(\begin{array}{c}
M_{x i} \\
M_{x y i}
\end{array}\right)+\sum_{j=1 . .4} K_{j i}^{(0)}\left(\begin{array}{c}
N_{x i} \\
N_{x y i}
\end{array}\right)+\sum_{j=1 . .4} K_{j i}^{(2)}\left(\begin{array}{c}
L_{x i} \\
L_{x y i}
\end{array}\right) \\
& +\sum_{j=1 . .4} K_{j i}^{(3)}\left(\begin{array}{c}
P_{x i} \\
P_{x y i}
\end{array}\right), \quad i=1 . .4
\end{aligned}
$$

Furthermore, we define the equivalent higher-order stress resultants based on the vector of primary parameters (equations (9) to (11), (15) and (16)) and the equilibrium equations (equations (27), (28) and (30)) as:

$$
\begin{aligned}
& \left(\begin{array}{c}
\hat{L}_{x 2} \\
\hat{L}_{x y 2}
\end{array}\right)=\left(\begin{array}{c}
L_{x 2} \\
L_{x y 2}
\end{array}\right)+\sum_{j=1 . .4} K_{j 5}^{(0)}\left(\begin{array}{c}
N_{x i} \\
N_{x y i}
\end{array}\right)+\sum_{j=1 . .4} K_{j 5}^{(1)}\left(\begin{array}{c}
M_{x i} \\
M_{x y i}
\end{array}\right)+\sum_{j=1 . .4} K_{j 5}^{(3)}\left(\begin{array}{c}
P_{x i} \\
P_{x y i}
\end{array}\right), \\
& \left(\begin{array}{c}
\hat{L}_{x 4} \\
\hat{L}_{x y 4}
\end{array}\right)=\left(\begin{array}{c}
L_{x 4} \\
L_{x y 4}
\end{array}\right)+\sum_{j=1 . .4} K_{j 6}^{(0)}\left(\begin{array}{c}
N_{x i} \\
N_{x y i}
\end{array}\right)+\sum_{j=1 . .4} K_{j 6}^{(1)}\left(\begin{array}{c}
M_{x i} \\
M_{x y i}
\end{array}\right)+\sum_{j=1 . .4} K_{j 6}^{(3)}\left(\begin{array}{c}
P_{x i} \\
P_{x y i}
\end{array}\right) \\
& \left(\begin{array}{c}
\hat{P}_{x 2} \\
\hat{P}_{x y 2}
\end{array}\right)=\left(\begin{array}{c}
P_{x 2} \\
P_{x y 2}
\end{array}\right)+\sum_{j=1 . .4} K_{j 7}^{(0)}\left(\begin{array}{c}
N_{x i} \\
N_{x y i}
\end{array}\right)+\sum_{j=1 . .4} K_{j 7}^{(1)}\left(\begin{array}{c}
M_{x i} \\
M_{x y i}
\end{array}\right)+\sum_{j=1 . .4} K_{j 7}^{(2)}\left(\begin{array}{c}
L_{x i} \\
L_{x y i}
\end{array}\right)
\end{aligned}
$$

Independently of the theory, the continuity against sum of membrane forces and equivalent moments should be satisfied:

$$
\left.\sum_{i=1 . .4}\left(\begin{array}{c}
N_{x i} \\
N_{x y i}
\end{array}\right)\right|_{x=+0} ^{(1)}=\left.\sum_{i=1 . .4}\left(\begin{array}{c}
N_{x i} \\
N_{x y i}
\end{array}\right)\right|_{x=-0} ^{(2)},\left.\left(\begin{array}{c}
\hat{M}_{x i} \\
\hat{M}_{x y i}
\end{array}\right)\right|_{x=+0} ^{(1)}=\left.\left(\begin{array}{c}
\hat{M}_{x i} \\
\hat{M}_{x y i}
\end{array}\right)\right|_{x=-0} ^{(2)}, i=1 . .4
$$


Apart from the above, for the SSDT, the continuity of the $L$ stress resultants is required as well:

$$
\left.\left(\begin{array}{c}
\hat{L}_{x 2} \\
\hat{L}_{x y 2}
\end{array}\right)\right|_{x=+0} ^{(1)}=\left.\left(\begin{array}{c}
\hat{L}_{x 2} \\
\hat{L}_{x y 2}
\end{array}\right)\right|_{x=-0} ^{(2)},\left.\left(\begin{array}{c}
\hat{L}_{x 4} \\
\hat{L}_{x y 4}
\end{array}\right)\right|_{x=+0} ^{(1)}=\left.\left(\begin{array}{c}
\hat{L}_{x 4} \\
\hat{L}_{x y 4}
\end{array}\right)\right|_{x=-0} ^{(2)}
$$

Finally, for the TSDT solution apart from equations (47) and (48), the equivalent $P$ stress resultants should be continuous:

$$
\left.\left(\begin{array}{c}
\hat{P}_{x 2} \\
\hat{P}_{x y 2}
\end{array}\right)\right|_{x=+0} ^{(1)}=\left.\left(\begin{array}{c}
\hat{P}_{x 2} \\
\hat{P}_{x y 2}
\end{array}\right)\right|_{x=-0} ^{(2)}
$$

Beside the above conditions, the core-core scenario (Scenario I) of the TSDT solution in accordance with equation (15), a so-called AC condition [105,106] is required:

$$
\left.\lambda_{(p) 3}\right|_{x=+0} ^{(0)}=\left.\sum_{j=1 . .7} K_{3 j}^{(3)} \psi_{(p) j}\right|_{x=-0} ^{(2)}, \quad p=x, y
$$

As a matter of fact for the FSDT equations (35), (36), (37), (40), (41), (42) and (47) mean $7+6+6+5+4+10+10$ conditions, i.e. altogether we have 48 , which is the sum of system matrix sizes $(22+26$, refer to Table 5$)$ and so the unknowns in the state space model. For the other theories and scenarios, the conditions can be collected and checked similarly.

\section{Energy release rates (ERRs) - The J-integrals}

The general 3D J-integral for delaminated composite Lévy plates have been defined in $[105,106]$ using four ESLs by SSDT and TSDT. The expressions for $J_{I I}$ and $J_{I I I}$ are:

$$
\begin{aligned}
J_{I I} & =\frac{1}{2} \sum_{i=1}^{k}\left\{\left(\left.N_{x 1(i)} \varepsilon_{x 1(i)}^{(0)}\right|_{x=+0}-\left.N_{x 2(i)} \varepsilon_{x 2(i)}^{(0)}\right|_{x=-0}\right)-\left(\left.N_{y 1(i)} \varepsilon_{y 1(i)}^{(0)}\right|_{x=+0}-\left.N_{y 2(i)} \varepsilon_{y 2(i)}^{(0)}\right|_{x=-0}\right)\right. \\
& +\left(\left.M_{x 1(i)} \varepsilon_{x 1(i)}^{(1)}\right|_{x=+0}-\left.M_{x 2(i)} \varepsilon_{x 2(i)}^{(1)}\right|_{x=-0}\right)-\left(\left.M_{y 1(i)} \varepsilon_{y 1(i)}^{(1)}\right|_{x=+0}-\left.M_{y 2(i)} \varepsilon_{y 2(i)}^{(1)}\right|_{x=-0}\right) \\
& +\left(\left.L_{x 1(i)} \varepsilon_{x 1(i)}^{(2)}\right|_{x=+0}-\left.L_{x 2(i)} \varepsilon_{x 2(i)}^{(2)}\right|_{x=-0}\right)-\left(\left.L_{y 1(i)} \varepsilon_{y 1(i)}^{(2)}\right|_{x=+0}-\left.L_{y 2(i)} \varepsilon_{y 2(i)}^{(2)}\right|_{x=-0}\right) \\
& \left.+\left(\left.P_{x 1(i)} \varepsilon_{x 1(i)}^{(3)}\right|_{x=+0}-\left.P_{x 2(i)} \varepsilon_{x 2(i)}^{(3)}\right|_{x=-0}\right)-\left(\left.P_{y 1(i)} \varepsilon_{y 1(i)}^{(3)}\right|_{x=+0}-\left.P_{y 2(i)} \varepsilon_{y 2(i)}^{(3)}\right|_{x=-0}\right)\right\}
\end{aligned}
$$




$$
\begin{aligned}
J_{I I I}= & -\frac{1}{2} \sum_{i=1}^{k}\left\{\left(\left.N_{x y 1(i)} \hat{\gamma}_{x y 1(i)}^{(0)}\right|_{x=+0}-\left.N_{x y 2(i)} \hat{\gamma}_{x y 2(i)}^{(0)}\right|_{x=-0}\right)\right. \\
& +\left(\left.M_{x y 1(i)} \hat{\gamma}_{x y 1(i)}^{(1)}\right|_{x=+0}-\left.M_{x y 2(i)} \hat{\gamma}_{x y 2(i)}^{(1)}\right|_{x=-0}\right) \\
& +\left(\left.L_{x y 1(i)} \hat{\gamma}_{x y 1(i)}^{(2)}\right|_{x=+0}-\left.L_{x y 2(i)} \hat{\gamma}_{x y 2(i)}^{(2)}\right|_{x=-0}\right) \\
& \left.+\left(\left.P_{x y 1(i)} \hat{\gamma}_{x y 1(i)}^{(3)}\right|_{x=+0}-\left.P_{x y 2(i)} \hat{\gamma}_{x y 2(i)}^{(3)}\right|_{x=-0}\right)\right\}
\end{aligned}
$$

where

$$
\hat{\gamma}_{x y p(i)}^{(q)}=\frac{\partial u_{p(i)}^{(q)}}{\partial y}-\frac{\partial v_{p(i)}^{(q)}}{\partial x}, \quad p=1 \text { or } 2, q=0,1,2,3
$$

are the so-called conjugate shear strains. In equations (51) and (52), $k=4$ because of the method of four ESLs. Equations (51) and (52) are valid up to third-order plates; however, it is easy to generalize for $n$th order plates. It is important to note that equations (51) and (52) agree with the concept given in [124].

As it can be seen, the mode-II J-integral is contributed by $N_{x}, N_{y}, M_{x}, M_{y}, L_{x}$, $L_{y}, P_{x}$ and $P_{y}$, on the other hand, the mode-III J-integral contains $N_{x y}, M_{x y}, L_{x y}$ and $P_{x y}$. In the sequel, the results of the method of four ESLs (FSDT, SSDT and TSDT) are presented and compared to the results of FE analysis obtained by using the VCCT method. It is important to note that although the code ANSYS is capable of determining the $\mathrm{J}$-integral numerically, it is not available for orthotropic materials. Therefore, the only alternative to calculate the ERRs in ANSYS is the VCCT. It is well-known that under static conditions and for a linear elastic material the J-integral is equivalent to the ERR, i.e. $G_{I I}=J_{I I}$ and $G_{I I I}=J_{I I I}$.

\section{Results and discussions}

Three different configurations are considered to check the performance of the model, the first scenario was the core failure (core-core delamination, scenario I) in a sandwich plate with 1-mm thick Al facesheets and a $25-\mathrm{mm}$ thick foam material. The delamination divided the core into $10 \mathrm{~mm}$ (top) and $15 \mathrm{~mm}$ (bottom) thick parts. The Al properties were $E=70 \mathrm{GPa}, v=0.3$ (isotropic), the foam properties were $E=23.1 \mathrm{MPa}, G=6.4 \mathrm{MPa}, v=0.4$ (isotropic) [125]. The second scenario is the delamination between the top facesheet and the core (scenario II). In this case, the 3-mm thick facesheets were made from crossply laminated composite $\left(E_{11}=E_{22}=E_{33}=82.4 \mathrm{GPa}, G_{12}=G_{23}=G_{13}=6.6 \mathrm{GPa}, v_{12}=v_{23}=v_{13}=0.4\right)$ [126], the core material was again a general foam with thickness of $25 \mathrm{~mm}$. It has to be noted that only the moduli are documented in [126], the shear moduli and the Poisson's ratio were chosen to obtain a positive definite material stiffness matrix. In the case of the third scenario, the delamination of the top facesheet was simulated (scenario III). The materials were the same as those of scenario II, but the 


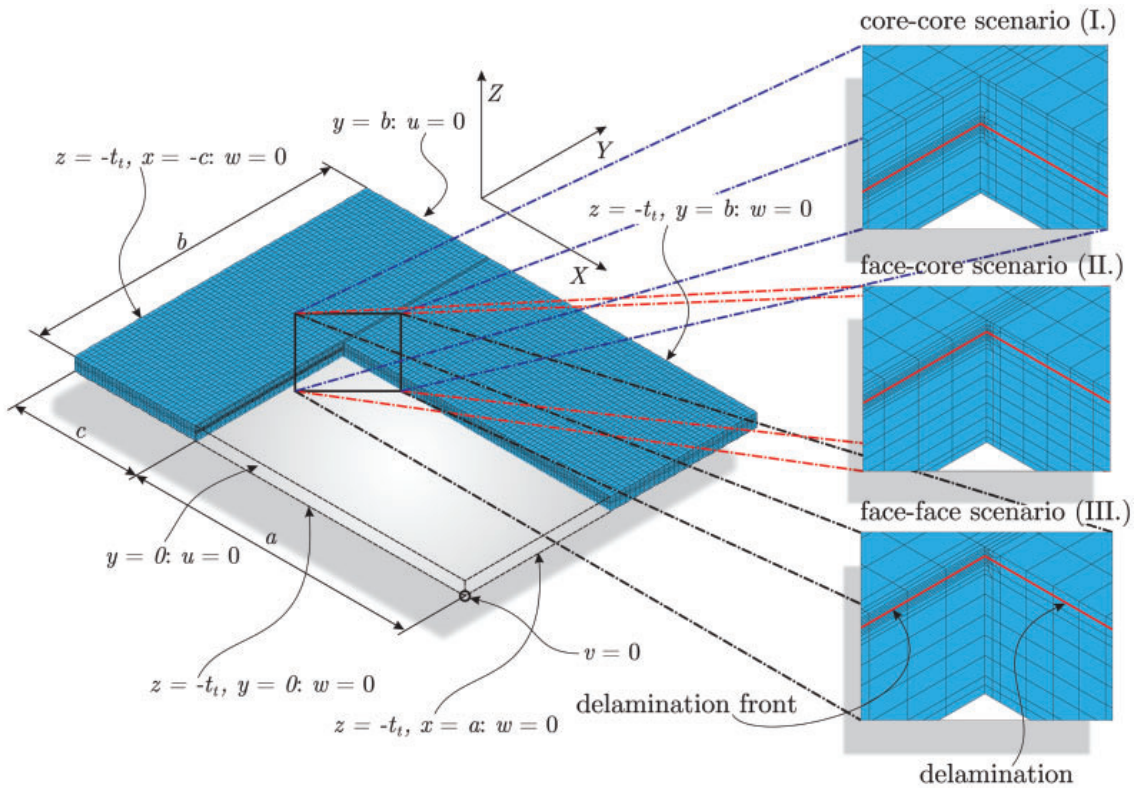

Figure 3. 3D FE model of a delaminated sandwich plate: Delamination tip details and boundary conditions.

thickness of the facesheets was increased to $4 \mathrm{~mm}$ and the delamination divided the top facesheet into two equal halves. The core thickness was $25 \mathrm{~mm}$. In each scenario, the uniformly distributed load was $0.005 \mathrm{~N} / \mathrm{m}^{2}$. The delamination length was $a=550 \mathrm{~mm}$, the uncracked length was $c=250 \mathrm{~mm}$, the width of the plate was $b=600 \mathrm{~mm}$. The calculation was carried out in the code MAPLE [127] based on the model presented in 'The SEKC', 'Equilibrium equations', 'Simply supported sandwich plate' and 'Energy release rates (ERRs) - The J-integrals' sections. The number of terms $(n)$ considered in the Lévy type solution was 7, the additional terms provided very negligible improvement in the results.

\section{Finite element models}

To verify and assess the analytical model, the 3D FE models of the plates were created in ANSYS environment using linear eight-noded brick-type SOLID elements. The model is shown in Figure 3 together with the delamination front details and boundary conditions. The virtual crack closure technique (VCCT) [128] was utilized to calculate the distribution of the ERRs along the delamination front. The size of the crack tip elements was $(\Delta x, \Delta y, \Delta z)=(0.5 \mathrm{~mm}, 0.5 \mathrm{~mm}, 10 \mathrm{~mm})$. The constraints of the FE model were imposed in order to have a statically determined problem in accordance with Figure 3. However, it is very important to note that equation (32) implies that the $u$ displacement component is zero along the 
a.

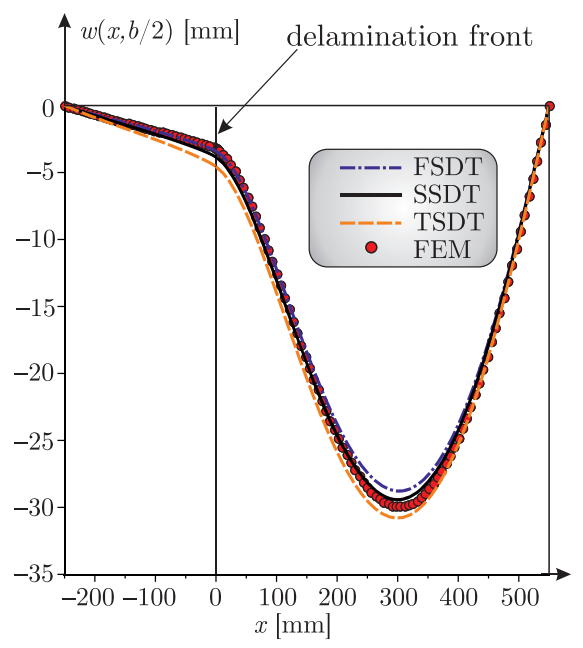

b.

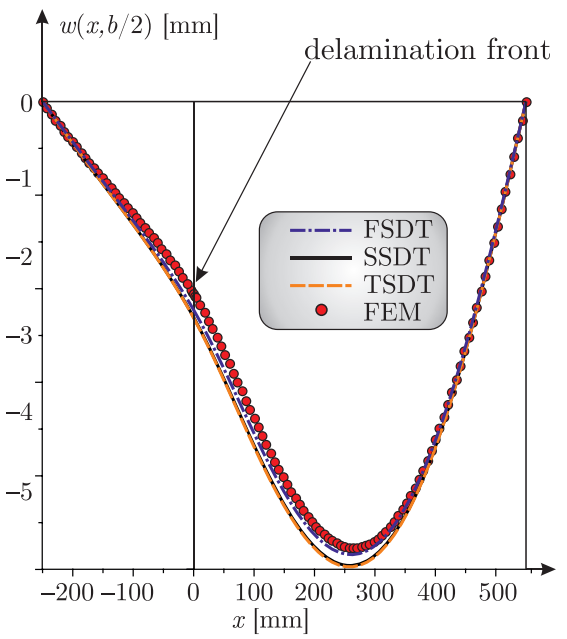

c.

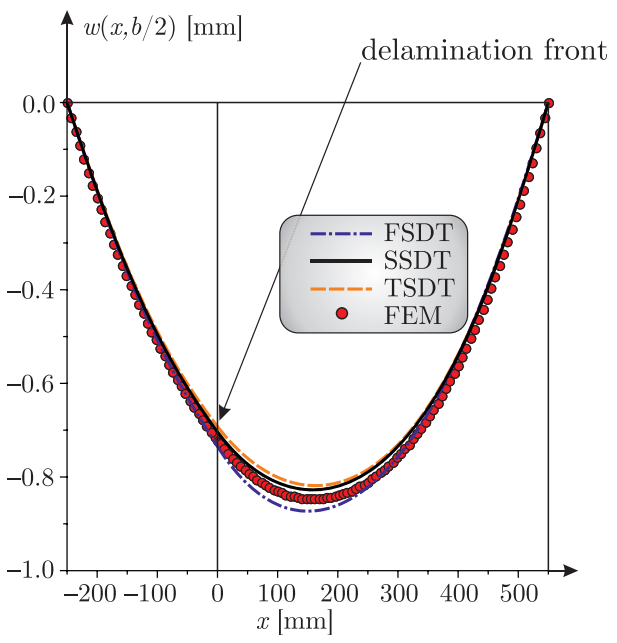

Figure 4. Deflections in the middle $(Y=b / 2)$ of the plates: (a) core-core failure (Scenario I), (b) face-core delamination (Scenario II) and (c) face-face delamination (Scenario III).

edges parallel to the $x$ axis in Figure 2. This condition is also shown in Figure 3 and needs to be imposed because of the soft core material and the relatively large thickness of the plate. The total number of elements was between 70,000 and 90,000 for each model in order not to overcome the capabilities of a notebook with average performance. A macro was written in the ANSYS Design and Parametric Language (ADPL) by using the nodal forces and displacements to calculate the distribution of $G_{I I}$ and $G_{I I I}$ along the delamination front. 


\section{Displacement and stress fields}

Figure 3 shows the deflections of the midlines $(Y=b / 2)$ of the plates for each scenario. It can be seen that the FSDT predicts a little bit smaller deflection compared to the FE solution. In contrast, the TSDT model overpredicts the numerical result. The SSDT solution seems to be the best for scenario I. In accordance with Figure 3(b), each model overpredicts the numerically determined deflection and the SSDT and TSDT solutions agree quite well. Finally, the SSDT was shown to perform the best in scenario III (Figure 4(c)). It has to be highlighted that the transverse elasticity of the plates was not taken into account in the analytical models.

Figure 5 presents the displacement and normal stress distributions for the corecore failure scenario in the sections located at the delamination front. The numerical model predicts high displacement perturbations in the vicinity of the delamination tip that the analytical models are not able to follow. In spite of that the $\sigma_{x}$ normal stress is approximated well by the analytical models. For $\sigma_{y}$, the agreement seems to be worst compared to the numerical model. The results of the face-core delamination scenario are documented in Figure 6. There is a strong
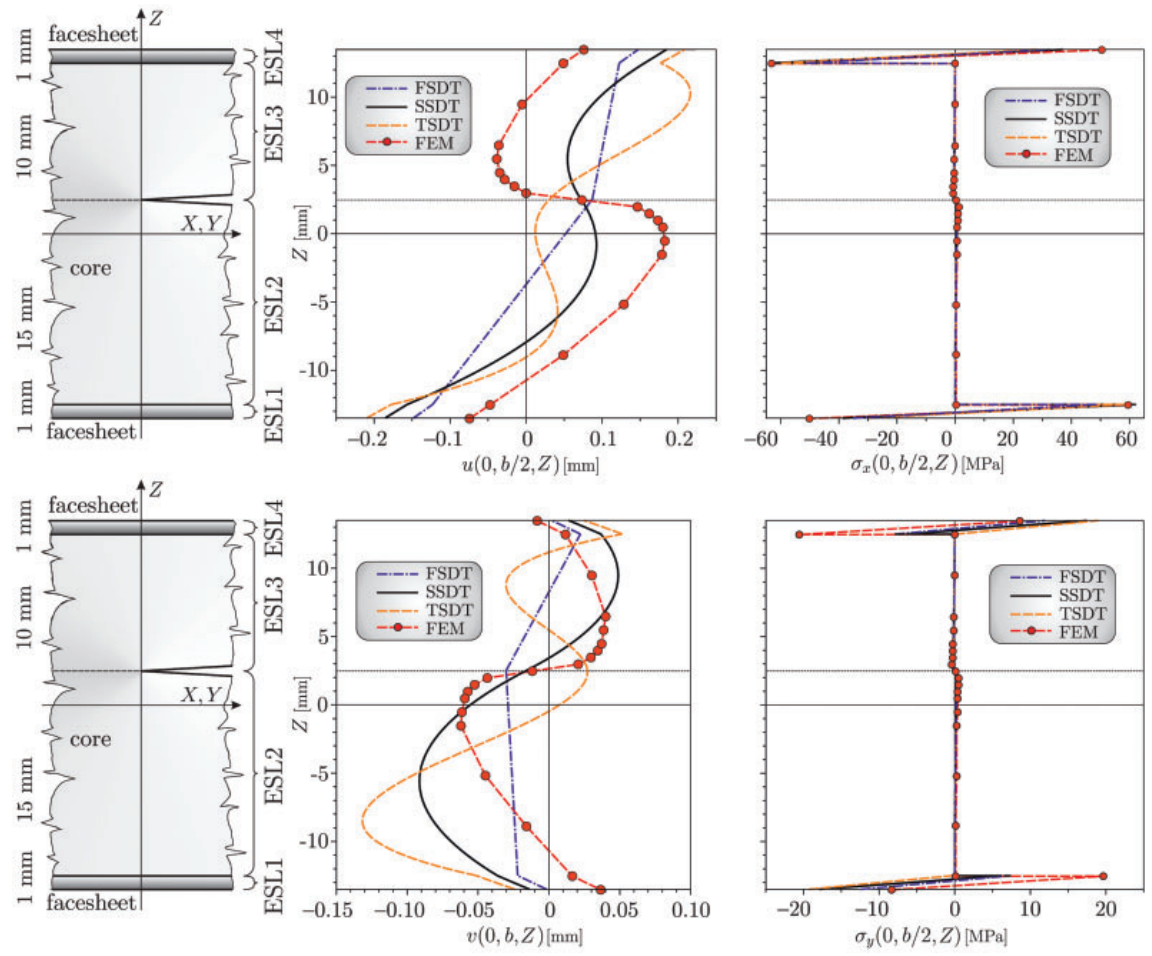

Figure 5. Distribution of the in-plane displacements $(u$ and $v)$ and the normal stresses $\left(\sigma_{x}\right.$ and $\sigma_{y}$ ) at the section of the delamination front, scenario l: core-core failure. 

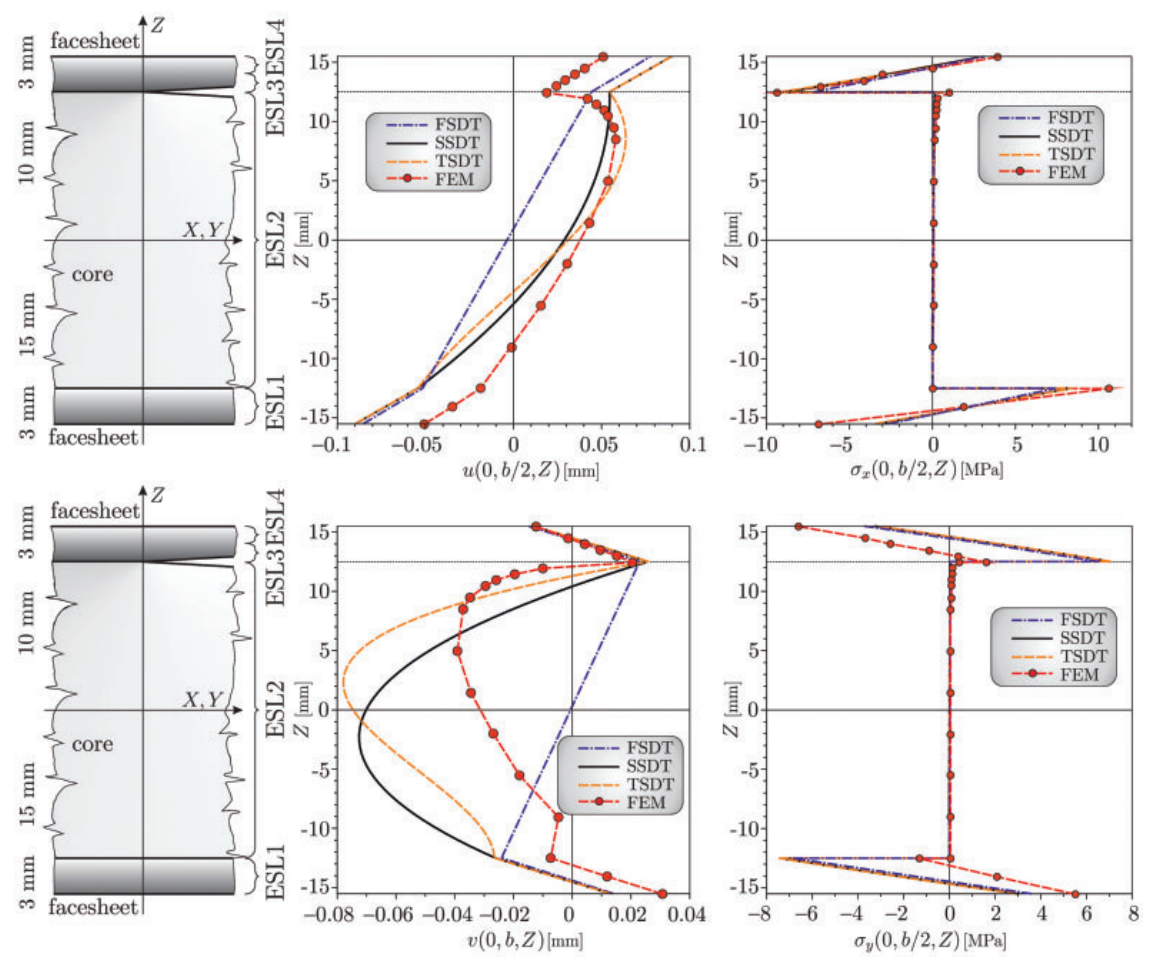

Figure 6. Distribution of the in-plane displacements $(u$ and $v)$ and the normal stresses $\left(\sigma_{x}\right.$ and $\left.\sigma_{y}\right)$ at the section of the delamination front, scenario II: face-core delamination.

change in the displacement distribution in the plane of the delamination. Among the analytical models, the SSDT and TSDT captures better the displacement distribution than the FSDT. Considering the normal stresses, again the $y$ component is approximated roughly by the analytical models.

The results of the face-face delamination scenario are plotted in Figure 7. Overall, based on Figure 7, it is the TSDT model that provides reasonable accuracy for the displacement and stress distributions.

The shear stresses were also calculated at certain sections located along the delamination front of the plate. Figure 8 depicts the distributions of shear stresses for the first scenario (core-core failure). The FE model computes a peak in the delamination plane, which increases with the mesh refinement. The analytical model does not predict any peaks; however, the shear stresses in the facesheets are determined in a different way. In the core material, the shear stresses are approximated well by the analytical model. In Figure 9, the transverse shear stresses are plotted relatively far from the delamination tip (from approximately equal distances) ahead and behind. Considering the differences in the deflection of the analytical models compared to that of the FE solution, the overall agreement is acceptable for all results plotted in Figure 9. For the face-core and the face-face 

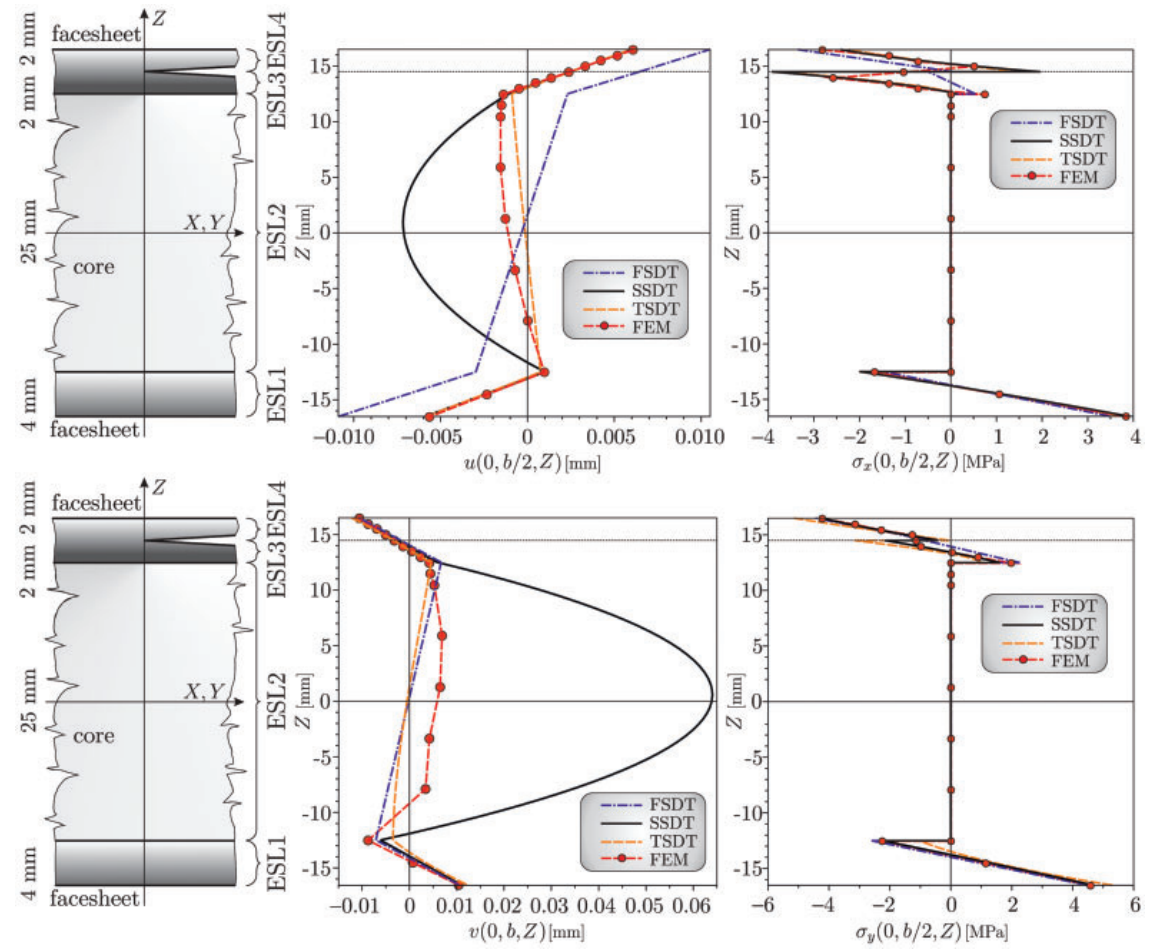

Figure 7. Distribution of the in-plane displacements $(u$ and $v)$ and the normal stresses $\left(\sigma_{x}\right.$ and $\left.\sigma_{y}\right)$ at the section of the delamination front, scenario III: face-face delamination.
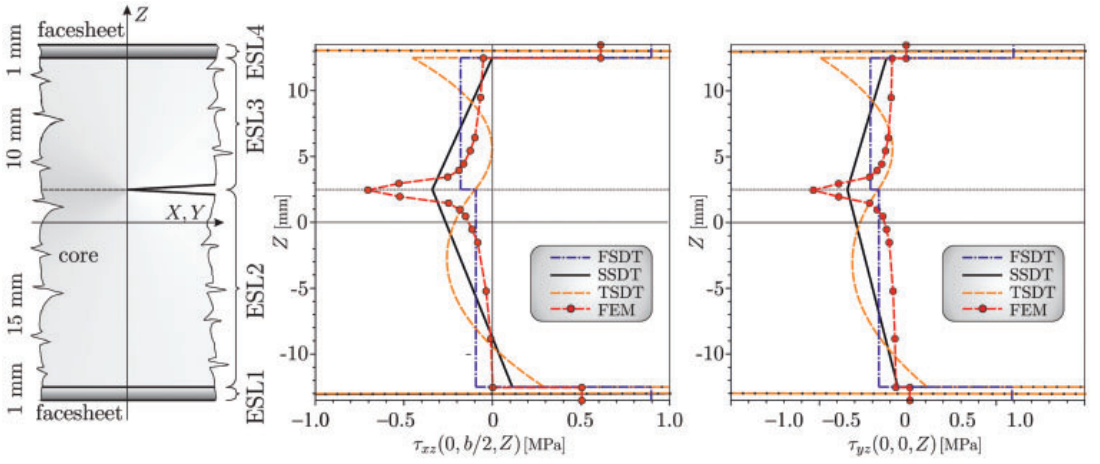

Figure 8. Distribution of the transverse shear stresses $\left(\tau_{x z}\right.$ and $\left.\tau_{y z}\right)$ at the section of the delamination front, scenario I: core-core delamination. 

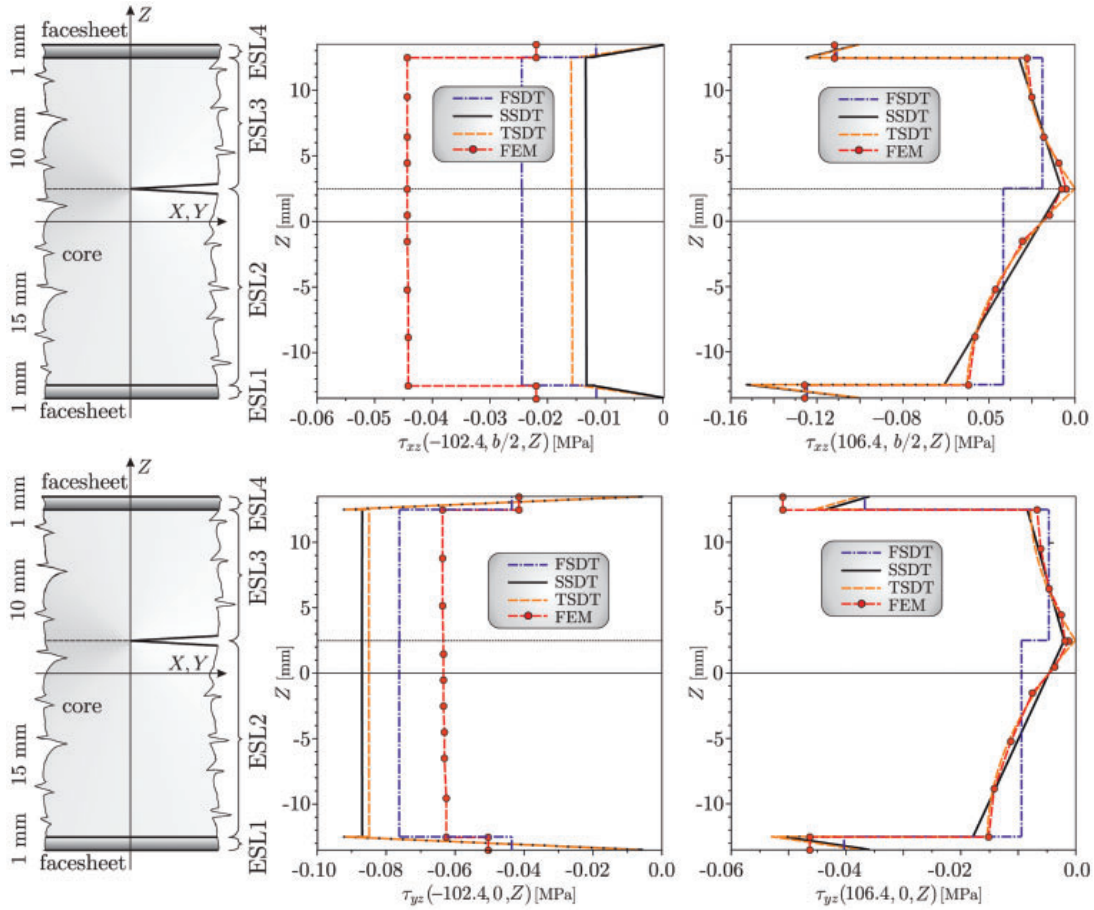

Figure 9. Distribution of the transverse shear stresses $\left(\tau_{x z}\right.$ and $\left.\tau_{y z}\right)$ ahead and behind the delamination front, scenario I: core-core delamination.
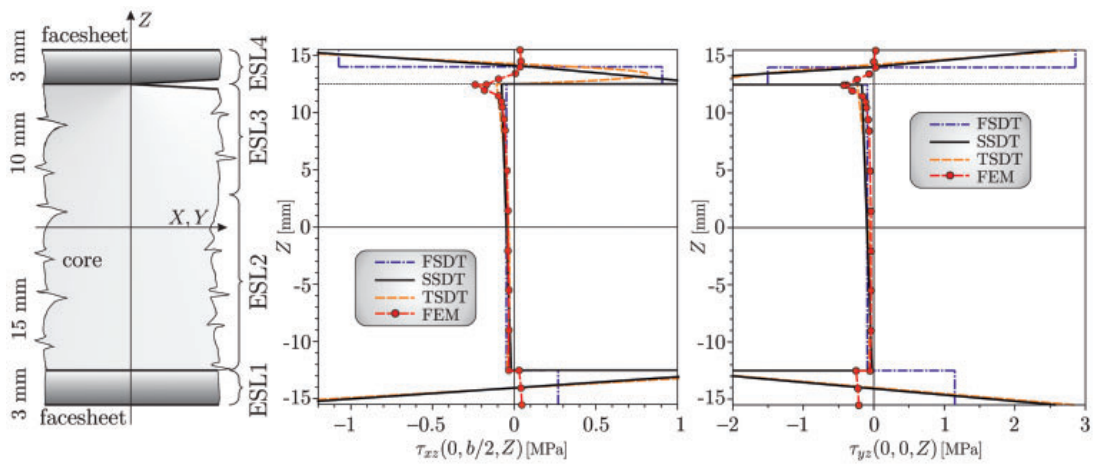

Figure 10. Distribution of the transverse shear stresses $\left(\tau_{x z}\right.$ and $\left.\tau_{y z}\right)$ at the section of the delamination front, scenario II: face-core delamination. 
scenarios, the shear stresses in sections located at the delamination front are shown in Figures 10 and 11. In the former case, a significant change is observed in the shear stresses of the top face sheet, which is not predicted by the numerical model. In the latter case, the agreement is much better, the change in the shear stresses by FEM is captured well by the analytical model. Finally, it has to be mentioned that the analytical models give an estimation of the area under the shear stress distributions and not the shape of the curves compared to the FE solution. That is the reason for the high peaks in Figures 10 and 11.
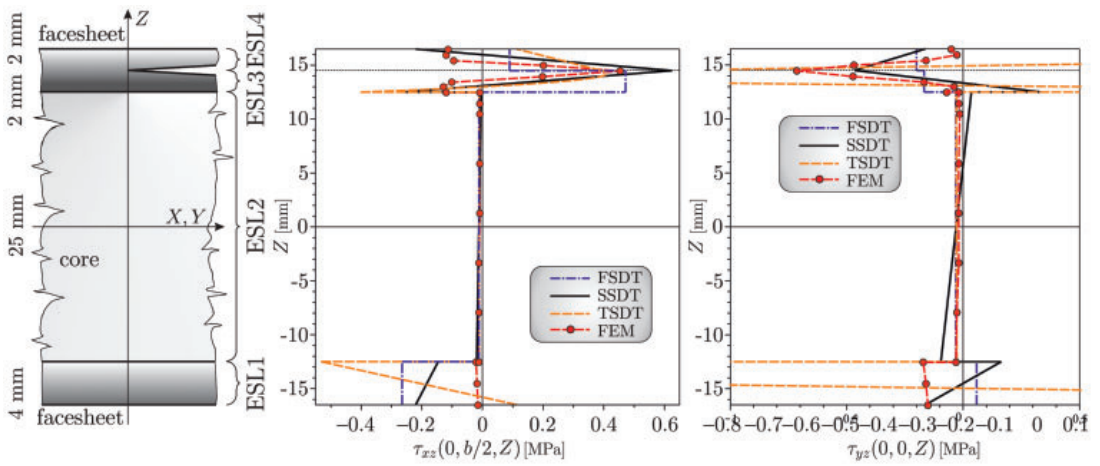

Figure II. Distribution of the transverse shear stresses $\left(\tau_{x z}\right.$ and $\left.\tau_{y z}\right)$ at the section of the delamination front, scenario III: face-face delamination.
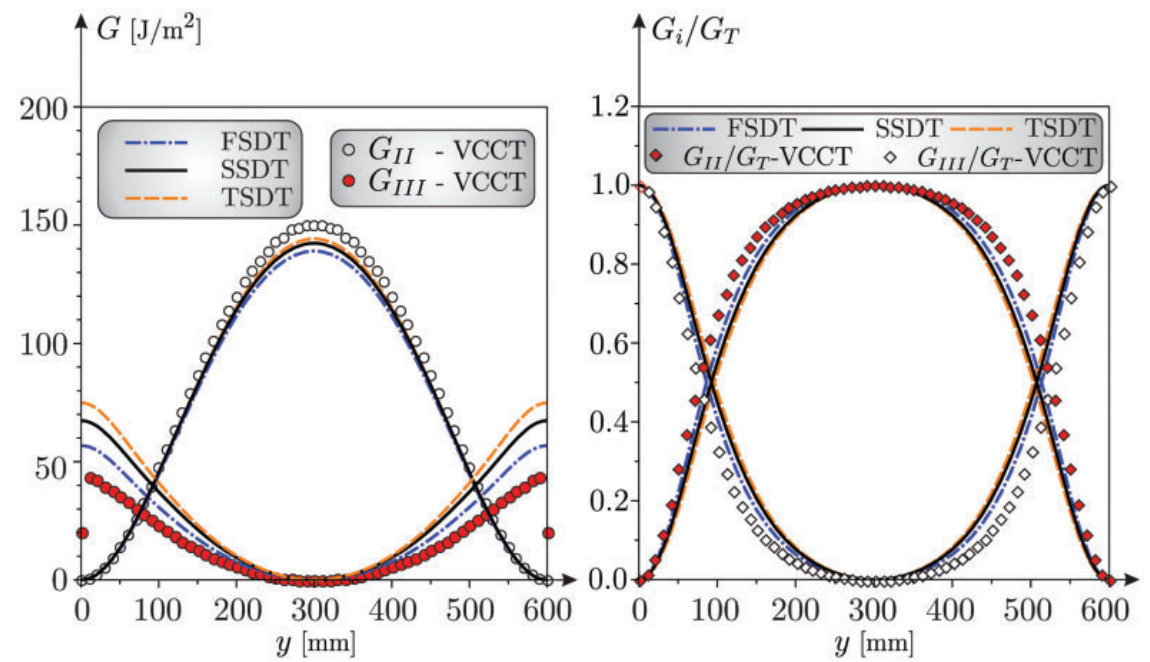

Figure 12. Distribution of the energy release rates and mode mixity along the delamination front, scenario l: core-core delamination. 


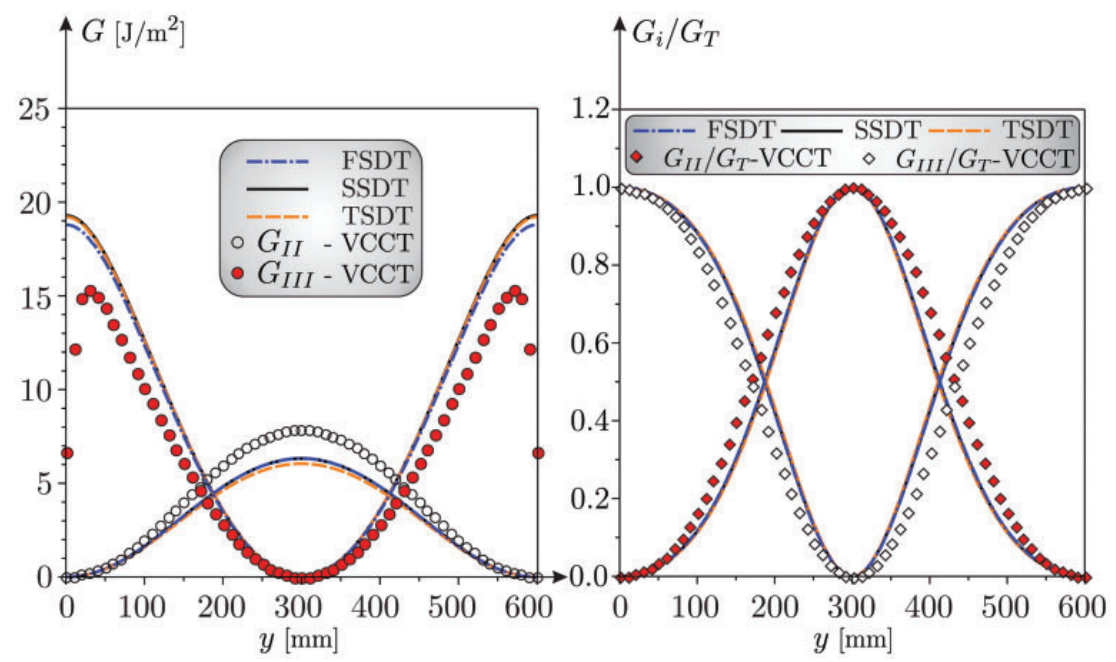

Figure 13. Distribution of the energy release rates and mode mixity along the delamination front, scenario II: face-core delamination.
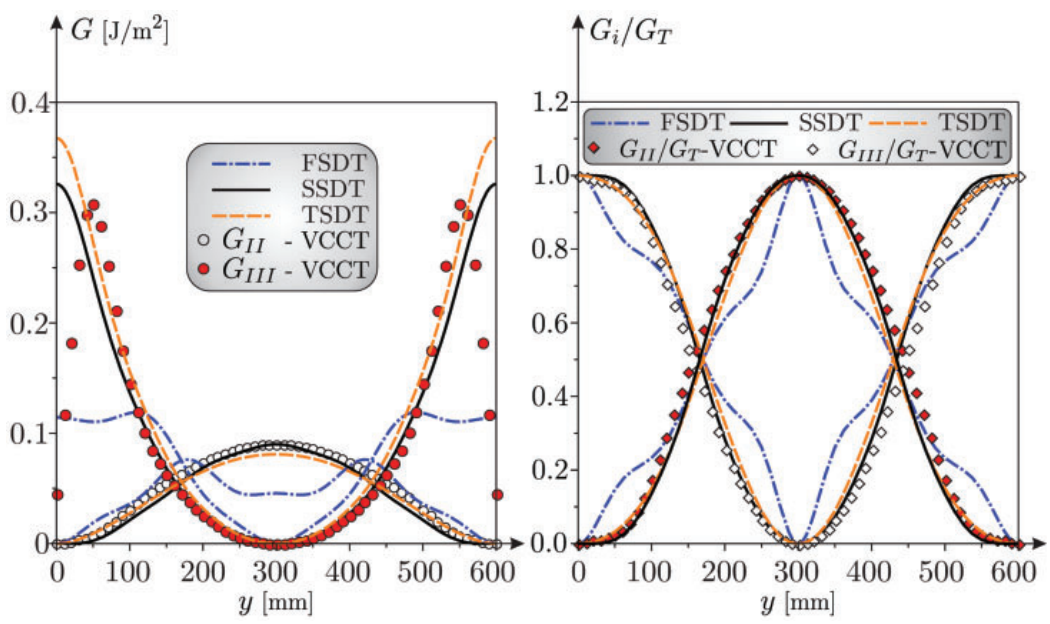

Figure 14. Distribution of the energy release rates and mode mixity along the delamination front, scenario III: face-face delamination.

\section{ERRs and mode mixity}

Figure 12 depicts the distribution of the ERRs and mode mixities along the delamination front for the core-core failure scenario. The mode-II ERR is very well predicted, while the mode-III ERR is overpredicted by the analytical models along the whole delamination front. Apparently, the FSDT model provides the 
best agreement with the FE results. The mode mixities show a very good agreement compared to the numerical model. The face-core and face-face delamination cases are documented in Figures 13 and 14. In Figure 13, each model behaves in a similar way, again, the FSDT seems to be the best. The results obtained for the face-face scenario in Figure 14 shows the failure of the FSDT solution in this case. On the contrary, the SSDT and TSDT solutions perform excellently in this critical case. At the edges, in each case, there is a little disagreement between the numerical and analytical results. The reason for that is the plate theory does not consider edge effects, on the contrary, in the FE model, the edges are stress concentrators.

Based on the obtained results, model size and agreement with the numerical results, the SSDT solution can be recommended to be the candidate of a possible shell finite element that can replace the computationally expensive 3D SOLID models.

\section{Conclusions}

The FSDT, SSDT and TSDT were applied to investigate three delamination scenarios in thick sandwich plates. The method of four ESLs was applied together with the SEKC. By formulating the governing equations for the delaminated and undelaminated parts of the plate and by using the Lévy type boundary conditions, the system of ODEs was derived. The solution was obtained by a state-space model. The boundary and continuity conditions were then provided and the role of the effective stress resultants were emphasised. A simply supported delaminated sandwich plate with uniformly distributed load was solved by the analytical model and the mechanical fields were determined. The finite element model of the plate was also created for three scenarios and a comparison was carried out with the analytical results. The three scenarios were core failure, face-core delamination and faceface delamination.

A first observation was that the deflection functions were quite accurate by the SSDT for scenarios I and III, and for scenario II, the FSDT should be ranked as the best. Considering the displacement and stress distributions at cross sections located along the delamination front, it was shown that the first-order plate theory is only a rough approximation of the FE results, while the SSDT and TSDT provided a better agreement. The numerical model predicted significant perturbations in the delamination tip that the analytical models were not able to follow. In spite of that, it was shown that the SSDT and TSDT solutions provide very good results for the ERR and mode ratio distributions. On the other hand, the FSDT failed to capture the distributions for the third scenario. The obtained results are promising, however to capture the mechanical fields better, it is also required to consider the transverse elasticity of the sandwich plate. The literature offers several possibilities to incorporate normal deformations into the model [55,66,76,96,129], which should be the next step in order to continue the research work. 


\section{Declaration of conflicting interests}

The author(s) declared no potential conflicts of interest with respect to the research, authorship, and/or publication of this article.

\section{Funding}

This work was supported by the János Bolyai Research Scholarship of the Hungarian Academy of Sciences and the Hungarian National Scientific Research Fund (OTKA) under Grant No. 44615-066-15 (108414).

\section{References}

1. Katunin A. Vibration-based spatial damage identification in honeycomb-core sandwich composite structures using wavelet analysis. Compos Struct 2014; 118: 385-391.

2. He Y, Tian G, Pan M, et al. Non-destructive testing of low-energy impact in CFRP laminates and interior defects in honeycomb sandwich using scanning pulsed eddy current. Compos Part B: Eng 2014; 59: 196-203.

3. Kilchert S, Johnson AF and Voggenreiter H. Modelling the impact behaviour of sandwich structures with folded composite cores. Compos Part A: Appl Sci Manuf 2014; 57: 16-26.

4. Zhang T, Yan Y and Li J. Experiments and numerical simulations of low-velocity impact of sandwich composite panels. Polym Compos 2017; 38: 646-656.

5. Xie ZH and Yan Q. Numerical modeling on low velocity impact on a foam core sandwich panel. Appl Mech Mater 2014; 527: 53-56.

6. Xie Z, Yan Q and Li X. Investigation on low velocity impact on a foam core composite sandwich panel. Steel Compos Struct 2014; 17: 159-172.

7. Thorsson SI, Xie J, Marek J, et al. Prediction of low-velocity impact damage in sandwich composite beams. In: 56th AIAA/ASCE/AHS/ASC structures, structural dynamics, and materials conference, Kissimmee, Florida, USA, 2015, pp.1-10.

8. Yang P, Shams SS, Slay A, et al. Evaluation of temperature effects on low velocity impact damage in composite sandwich panels with polymeric foam cores. Compos Struct 2015; 129: 213-223.

9. Scarponi C, Briotti G, Barboni R, et al. Impact testing on composites laminates and sandwich panels. J Compos Mater 1996; 30: 1873-1911.

10. Burlayenko VN and Sadowski T. A numerical study of the dynamic response of sandwich plates initially damaged by low-velocity impact. Comput Mater Sci 2012; 52: $212-216$.

11. Guan ZW, Aktas A, Potluri P, et al. The blast resistance of stitched sandwich panels. Int $J$ Impact Eng 2014; 65: 137-145.

12. Khoran M, Ghabezi P, Frahani M, et al. Investigation of drilling composite sandwich structures. Int J Adv Manuf Technol 2014; 76: 1927-1936.

13. Liu Q and Zhao Y. A parametric study on natural frequency of sandwich panel using refined shear model. In: ASME 2002 engineering technology conference on energy. vol. 2. American Society of Mechanical Engineers, Petroleum Division (Publication) PD, Houston, TX, USA, 4-5 February 2002, pp.535-540.

14. Singh AK, Davidson BD, Eisenberg DP, et al. Damage characterization of quasi-statically indented composite sandwich structures. J Compos Mater 2013; 47: 1211-1229.

15. Giunta G, Catapano A and Belouettar S. Failure indentation analysis of composite sandwich plates via hierarchical models. J Sandw Struct Mater 2013; 15: 45-70. 
16. Saadati $\mathrm{M}$ and Sadighi M. Indentation law for lightweight sandwich plates. Proc Inst Mech Eng Part G: J Aerosp Eng 2011; 225: 915-928.

17. Xiao $\mathbf{J}$ and Batra RC. Delamination in sandwich panels due to local water slamming loads. J Fluids Struct 2014; 48: 122-155.

18. Avery JL III and Sankar BV. Compressive failure of sandwich beams with debonded face-sheets. J Compos Mater 2000; 34: 1176-1199.

19. Ovesy H, Naghinejad M and Kharazi M. Delamination growth speed analysis in a compressed composite laminate based on first-order shear deformation theory. J Compos Mater 2016; 50: 849-857.

20. Naghinejad M and Ovesy HR. Calculation of total energy release rate in post-local buckling delamination of composite laminates. J Compos Mater 2017; 51: 623-635.

21. Chirica I and Beznea EF. Buckling analysis of the composite plates with delaminations. Comput Mater Sci 2011; 50: 1587-1591.

22. Chirica I and Beznea EF. Buckling behavior of the multiple delaminated composite plates under shear and axial compression. Comput Mater Sci 2012; 64: 173-178.

23. Juhász Z and Szekrényes A. Progressive buckling of a simply supported delaminated orthotropic rectangular composite plate. Int J Solids Struct 2015; 69: 217-229.

24. Juhász Z and Szekrényes A. Estimation of local delamination buckling in orthotropic composite plates using Kirchhoff plate finite elements. Math Probl Eng 2015; 2015: 1-14.

25. Matsuda H, Matsubara G, Kuraishi A, et al. Effect of crack arrester on fatigue crack growth in foam core sandwich panel under mode I type loading. Compos Part A: Appl Sci Manuf 2014; 56: 36-43.

26. Fotouhi M, Saeedifar M, Sadeghi S, et al. Investigation of the damage mechanisms for mode I delamination growth in foam core sandwich composites using acoustic emission. Struct Health Monitor 2015; 14: 265-280.

27. Pradeep KR, Nageswara Rao B, Sivakumar SM, et al. Interface fracture assessment on sandwich DCB specimens. J Reinf Plast Compos 2010; 29: 1963-1977.

28. Pradeep KR, Nageswara Rao B, Srinivasan SM, et al. Interface fracture assessment on honeycomb sandwich composite DCB specimens. Eng Fract Mech 2012; 93: 108-118.

29. Papanicolaou GC and Bakos D. Effect of treatment conditions on the mode I delamination fracture toughness of sandwich structures. J Compos Mater 1995; 29: 2295-2316.

30. Hajikhani M, Ahmadi M, Farjpour M, et al. Strain energy release rate assessment in mode I delamination of foam core sandwich composites by acoustic emission. $J$ Compos Mater 2011; 45: 2271-2277.

31. Quispitupa A, Berggreen C and Carlsson LA. Design analysis of the mixed mode bending sandwich specimen. J Sandw Struct Mater 2010; 12: 253-272.

32. Quispitupa A, Berggreen C and Carlsson LA. Face/core interface fracture characterization of mixed mode bending sandwich specimens. Fatig Fract Eng Mater Struct 2011; 34: 839-853.

33. Grau D, Qiu X and Sankar B. Relation between interfacial fracture toughness and mode-mixity in honeycomb core sandwich composites. J Sandw Struct Mater 2006; 8: 187-203.

34. Carlsson LA and Kardomateas GA. Structural and failure mechanics of sandwich composites. Dordrecht, Heidelberg, London, New York: Springer, 2011.

35. Rizov V. Mode III fracture study of foam core composite sandwich beams. Cell Polym 2012; 31: 315-328. 
36. Rodríguez-González JA, May-Pat A and Avilés F. A beam specimen to measure the face/core fracture toughness of sandwich materials under a tearing loading mode. Int $J$ Mech Sci 2014; 79: 84-94.

37. Rizov V. Mixed-Mode II/III fracture in foam core sandwich beams. Cell Polym 2014; 33: $287-300$.

38. Rizov V. Analysis of mixed-mode II/III fracture in sandwich beams. Multidiscip Model Mater Struct 2015; 11: 75-87.

39. Rizov V. Fracture in foam core composite sandwich beams under mixed-mode I/II/III loading conditions. Strength Fract Complex 2014; 8: 153-165.

40. Kossa A. A new biaxial compression fixture for polymeric foams. Polym Test 2015; 45: 47-51.

41. Li $\mathrm{J}$ and Narita $\mathrm{Y}$. The effect of aspect ratios and edge conditions on the optimal damping design of thin soft core sandwich plates and beams. J Vib Control 2014; 20: 266-279.

42. Foo CC, Chai GB and Seah LK. Mechanical properties of Nomex material and Nomex honeycomb structure. Compos Struct 2007; 80: 588-594.

43. Schwingshackl CW, Aglietti GS and Cunningham PR. Determination of honeycomb material properties: Existing theories and an alternative dynamic approach. $J$ Aerosp Eng 2006; 19: 177-183.

44. Chirica I, Beznea EF, et al. Influence of the honeycomb geometry on the sandwich composite plate behavior. Adv Mater Res 2017; 1143: 139-144.

45. Kollár LP and Springer GS. Mechanics of composite structures. Cambridge, New York, Melbourne, Madrid, Cape Town, Singapore, São Paolo: Cambridge University Press, 2003.

46. Allen HG. Analysis and design of structural sandwich panels, 1st ed. Oxford, London, Edinburgh, New York, Toronto, Sydney, Paris, Braunschweig: Pergamon Press, 1969.

47. Vinson JR. The behavior of sandwich structures of isotropic and composite materials. Lancaster, PA: Technomic Publishing Company Inc, 1999.

48. Demasi L. 2D, quasi 3D and 3D exact solutions for bending of thick and thin sandwich plates. J Sandw Struct Mater 2008; 10: 271-310.

49. Plagianakos TS and Papadopoulos EG. Higher-order 2-D/3-D layerwise mechanics and finite elements for composite and sandwich composite plates with piezoelectric layers. Aerosp Sci Technol 2015; 40: 150-163.

50. Suzuki K and Kimpara I. Multilayered and selective higher-order-deformable sandwich finite element modeling for numerical accuracy improvement. Composites Technologies for 2020. Cambridge, England: Woodhead Publishing Limited, 2004.

51. Fu M, Liu Z and Yin J. Delamination analysis of sandwich beam: High-order theory. AIAA J 2002; 40: 981-986.

52. Goswami S and Becker W. Analysis of sandwich plates with compressible core using layerwise refined plate theory and interface stress continuity. J Compos Mater 2016; 50: 201-217.

53. Elmalich D and Rabinovitch O. Twist in soft-core sandwich plates. J Sandw Struct Mater 2014; 16: 577-613.

54. Nayak AK, Shenoi RA and Moy SSJ. Analysis of damped composite sandwich plates using plate bending elements with substitute shear strain fields based on Reddy's higherorder theory. Proc Inst Mech Eng Part C: J Mech Eng Sci 2002; 216: 591-606. 
55. Pandit MK, Sheikh AH and Singh BN. Analysis of laminated sandwich plates based on an improved higher order zigzag theory. J Sandw Struct Mater 2010; 12: 307-326.

56. Ferreira AJM, Roque CMC, Carrera E, et al. Analysis of sandwich plates by radial basis functions collocation, according to Murakami's Zig-Zag theory. J Sandw Struct Mater 2012; 14: 505-524.

57. Tian A, Ye R and Chen Y. A new higher order analysis model for sandwich plates with flexible core. J Compos Mater 2016; 50: 949-961.

58. Malekzadeh K and Sayyidmousavi A. Free vibration analysis of sandwich plates with a uniformly distributed attached mass, flexible core, and different boundary conditions. J Sandw Struct Mater 2010; 12: 709-732.

59. Marjanović M and Vuksanović D. Layerwise solution of free vibrations and buckling of laminated composite and sandwich plates with embedded delaminations. Compos Struct 2014; 108: 9-20.

60. Akbarov SD, Yahnioglu $\mathrm{N}$ and Tekin A. Buckling delamination of a rectangular viscoelastic sandwich plate containing interface inner cracks. J Eng Mech 2014; 140: 134-148.

61. Grover N, Singh BN and Maiti DK. Free vibration and buckling characteristics of laminated composite and sandwich plates implementing a secant function based shear deformation theory. Proc Inst Mech Eng Part C: J Mech Eng Sci 2015; 229: 391-406.

62. Sahoo R and Singh BN. Assessment of zigzag theories for free vibration analysis of laminated-composite and sandwich plates. Proc Inst Mech Eng Part G: J Aerosp Eng 2015; 229: 1931-1949.

63. Iurlaro L, Gherlone M, Di Sciuva M, et al. Assessment of the Refined Zigzag Theory for bending, vibration, and buckling of sandwich plates: A comparative study of different theories. Compos Struct 2013; 106: 777-792.

64. Ren X and Chen W. Free vibration analysis of laminated and sandwich plates using quadrilateral element based on an improved zig-zag theory. J Compos Mater 2011; 45: $2173-2187$.

65. Jensen AE and Irgens F. Thickness vibrations of sandwich plates and beams and delamination detection. J Intell Mater Syst Struct 1999; 10: 46-55.

66. Pandit MK, Sheikh AH and Singh BN. Vibration characteristic of laminated sandwich plates with soft core based on an improved higher-order zigzag theory. Proc Inst Mech Eng Part C: J Mech Eng Sci 2008; 222: 1443-1451.

67. Nayak AK and Shenoi RA. Assumed strain finite elements for buckling and vibration analysis of initially stressed damped composite sandwich plates. J Sandw Struct Mater 2005; 7: 307-334.

68. Garg AK, Khare RK and Kant T. Higher-order closed-form solutions for free vibration of laminated composite and sandwich shells. J Sandw Struct Mater 2006; 8: 205-235.

69. Meunier M and Shenoi R. Free vibration analysis of composite sandwich plates. Proc Inst Mech Eng Part C: J Mech Eng Sci 1999; 213: 715-727.

70. Lopatin AV and Morozov EV. Symmetrical vibration modes of composite sandwich plates. J Sandw Struct Mater 2011; 13: 189-211.

71. Morozov EV and Lopatin AV. Fundamental frequency of fully clamped composite sandwich plate. J Sandw Struct Mater 2010; 12: 591-619. 
72. Morozov EV and Lopatin AV. Buckling analysis and design of a uniformly compressed rectangular composite sandwich plate with two parallel simply supported edges and another two edges clamped. J Sandw Struct Mater 2014; 16: 88-107.

73. Topdar P, Sheikh A and Dhang N. Finite element analysis of composite and sandwich plates using a continuous inter-laminar shear stress model. J Sandw Struct Mater 2003; 5: 207-231.

74. Darilmaz K. Analysis of sandwich plates: A three-dimensional assumed stress hybrid finite element. J Sandw Struct Mater 2012; 14: 487-501.

75. Nayak A, Moy SJ and Shenoi R. Quadrilateral finite elements for multilayer sandwich plates. J Strain Anal Eng Des 2003; 38: 377-392.

76. Linke M, Wohlers $\mathrm{W}$ and Reimerdes HG. Finite element for the static and stability analysis of sandwich plates. J Sandw Struct Mater 2007; 9: 123-142.

77. Kheirikhah MM, Khadem M and Farahpour P. Bending analysis of soft core sandwich plates with embedded shape memory alloy wires using three-dimensional finite element method. Proc Inst Mech Eng Part L: J Mater Des Appl 2012; 226: 186-202.

78. Goswami S. A finite element investigation on the effect of cross-sectional warping on flexural response of laminated composites and sandwiches using higher-order shear deformation theory. J Reinf Plast Compos 2005; 24: 1587-1604.

79. Frostig Y. Non-linear behavior of a face-sheet debonded sandwich panel-Thermal effects. Int J Non-Linear Mech 2014; 64: 1-25.

80. Kulkarni SA and Bajoria KM. Geometrically nonlinear analysis of smart thin and sandwich plates. $J$ Sandw Struct Mater 2006; 8: 321-341.

81. Burlayenko VN and Sadowski T. Nonlinear dynamic analysis of harmonically excited debonded sandwich plates using finite element modelling. Compos Struct 2014; 108: 354-366.

82. Burlayenko VN and Sadowski T. Transient dynamic response of debonded sandwich plates predicted with finite element analysis. Meccanica 2014; 49: 2617-2633.

83. Jayatilake IN, Karunasena W and Lokuge W. Dynamic analysis of multilayer GFRP sandwich slabs with interlayer delaminations. In: 8th Australasian congress on applied mechanics (ACAM 8), Melbourne, Australia, 2014, pp.665-672.

84. Makhecha D, Ganapathi M and Patel B. Vibration and damping analysis of laminated/ sandwich composite plates using higher-order theory. J Reinf Plast Compos 2002; 21: 559-575.

85. Elmalich D and Rabinovitch O. A high-order finite element for dynamic analysis of soft-core sandwich plates. J Sandw Struct Mater 2012; 14: 525-555.

86. Roque CMC, Ferreira AJM and Jorge RMN. Free vibration analysis of composite and sandwich plates by a trigonometric layerwise deformation theory and radial basis functions. J Sandw Struct Mater 2006; 8: 497-515.

87. Chakrabarti A. Dynamic instability of imperfect sandwich laminates by an efficient FE model. J Reinf Plast Compos 2009; 28: 393-408.

88. Hernández-Pérez A, Avilés F and Carlsson LA. First-order shear deformation analysis of the sandwich plate twist specimen. J Sandw Struct Mater 2012; 14: 229-245.

89. Bourada M, Tounsi A, Houari MSA, et al. A new four-variable refined plate theory for thermal buckling analysis of functionally graded sandwich plates. J Sandw Struct Mater 2012; 14: 5-33.

90. Bessaim A, Houari MSA, Tounsi A, et al. A new higher-order shear and normal deformation theory for the static and free vibration analysis of sandwich 
plates with functionally graded isotropic face sheets. J Sandw Struct Mater 2013; 15: 671-703.

91. Meziane MAA, Abdelaziz HH and Tounsi A. An efficient and simple refined theory for buckling and free vibration of exponentially graded sandwich plates under various boundary conditions. J Sandw Struct Mater 2014; 16: 293-318.

92. Iurlaro L, Gherlone M and Di Sciuva M. Bending and free vibration analysis of functionally graded sandwich plates using the Refined Zigzag Theory. J Sandw Struct Mater 2014; 16: 669-699.

93. Taibi FZ, Benyoucef S, Tounsi A, et al. A simple shear deformation theory for thermomechanical behaviour of functionally graded sandwich plates on elastic foundations. J Sandw Struct Mater 2015; 17: 99-129.

94. Nguyen TK, Vo TP and Thai HT. Vibration and buckling analysis of functionally graded sandwich plates with improved transverse shear stiffness based on the firstorder shear deformation theory. Proc Inst Mech Eng Part C: J Mech Eng Sci 2014; 228: 2110-2131.

95. Taj MG, Chakrabarti A and Talha M. Bending analysis of functionally graded skew sandwich plates with through-the thickness displacement variations. J Sandw Struct Mater 2014; 16: 210-248.

96. Kamarian S, Yas MH and Pourasghar A. Free vibration analysis of three-parameter functionally graded material sandwich plates resting on Pasternak foundations. $J$ Sandw Struct Mater 2013; 15: 292-308.

97. Kiani Y, Bagherizadeh E and Eslami MR. Thermal and mechanical buckling of sandwich plates with FGM face sheets resting on the Pasternak elastic foundation. Proc Inst Mech Eng Part C: J Mech Eng Sci 2012; 226: 32-41.

98. Szekrényes A. Analysis of classical and first-order shear deformable cracked orthotropic plates. J Compos Mater 2014; 48: 1441-1457.

99. Szekrényes A. The system of exact kinematic conditions and application to delaminated first-order shear deformable composite plates. Int J Mech Sci 2013; 77: 17-29.

100. Szekrényes A. Interface fracture in orthotropic composite plates using second-order shear deformation theory. Int J Dam Mech 2013; 22: 1161-1185.

101. Szekrényes A. Antiplane-inplane shear mode delamination between two second-order shear deformable composite plates. Math Mech Solids 2017; 22: 259-282.

102. Szekrényes A. Stress and fracture analysis in delaminated orthotropic composite plates using third-order shear deformation theory. Appl Math Modell 2014; 38: 3897-3916.

103. Szekrényes A. Application of Reddy's third-order theory to delaminated orthotropic composite plates. Eur J Mech A/Solids 2014; 43: 9-24.

104. Szekrényes A. Bending solution of third-order orthotropic Reddy plates with asymmetric interfacial crack. Int J Solids Struct 2014; 51: 2598-2619.

105. Szekrényes A. Nonsingular crack modelling in orthotropic plates by four equivalent single layers. Eur J Mech A/Solids 2016; 55: 73-99.

106. Szekrényes A. Semi-layerwise analysis of laminated plates with nonsingular delamination-The theorem of autocontinuity. Appl Math Modell 2016; 40: 1344-1371.

107. Singh VK and Panda SK. Nonlinear free vibration analysis of single/doubly curved composite shallow shell panels. Thin-Wall Struct 2014; 85: 341-349.

108. Singh VK, Mahapatra TR and Panda SK. Nonlinear flexural analysis of single/doubly curved smart composite shell panels integrated with PFRC actuator. Eur J Mech-A/ Solids 2016; 60: 300-314. 
109. Singh VK, Mahapatra TR and Panda SK. Nonlinear transient analysis of smart laminated composite plate integrated with PVDF sensor and AFC actuator. Compos Struct 2016; 157: 121-130.

110. Kulmani M and Panda SK. Geometrical nonlinear free vibration analysis of FG-CNT reinforced composite flat panel under uniform thermal field. Compos Struct 2016; 143: 336-346.

111. Kotousov A, Lazzarin P, Berto F, et al. Three-dimensional stress states at crack tip induced by shear and anti-plane loading. Eng Fract Mech 2013; 108: 65-74.

112. Kotousov A, Berto F, Lazzarin P, et al. Three dimensional finite element mixed fracture mode under anti-plane loading of a crack. Theor Appl Fract Mech 2012; 62: 26-33.

113. Petrolito J. Vibration and stability analysis of thick orthotropic plates using hybridTrefftz elements. Appl Math Modell 2014; 338: 5858-5869.

114. Izadi $\mathrm{M}$ and Tahani $\mathrm{M}$. Analysis of interlaminar stresses in general cross-ply laminates with distributed piezoelectric actuators. Compos Struct 2010; 92: 757-768.

115. Davidson BD, Yu L and $\mathrm{Hu} \mathrm{H}$. Determination of energy release rate and mode mix in three-dimensional layered structures using plate theory. Int J Fract 2000; 105: 81-104.

116. Zou Y, Tong L and Steven GP. Vibration-based model-dependent damage (delamination) identification and health monitoring for composite structures-A review. J Sound Vib 2000; 230: 357-378.

117. Reddy JN. Mechanics of laminated composite plates and shells-Theory and analysis. Boca Raton, London, New York, Washington DC: CRC Press, 2004.

118. Chou PC and Pagano NJ. Elasticity-Tensor, dyadic, and engineering approaches. Princeton, New Jersey, Toronto, London: D. Van Nostrand Company, Inc, 1967.

119. Anderson TL. Fracture mechanics - Fundamentals and applications, 3rd ed. Boca Raton, London, New York, Singapore: CRC Press, Taylor \& Francis Group, 2005.

120. Hills DA, Kelly PA, Dai DN, et al. Solution of crack problems: The distributed dislocation technique. Dordrecht, Boston, London: Kluwer Academic Publishers, 1996.

121. Vinson JR. Plate and panel structures of isotropic, composite and piezoelectric materials, including sandwich construction. Dordrecht: Springer, 2010.

122. Jianqiao Y. Laminated composite plates and shells-3D modelling. London, Berlin, Heidelberg, New York, Hong Kong, Milan, Paris, Tokyo: Springer, 2003.

123. Hatch MR. Vibration simulation using MATLAB and ANSYS. Boca Raton, London, New York, Washington DC: Chapman \& Hall/CRC, 2001.

124. Rigby RH and Aliabadi MH. Decomposition of the mixed-mode $J$-integral - revisited. Int J Solids Struct 1998; 35: 2073-2099.

125. Witkiewicz W and Zieliński A. Properties of the polyurethane (PU) light foams. $A d v$ Mater Sci 2006; 6: 35-51.

126. Pratt WF, Allen MS and Skousen TJ. Highly damped lightweight wavy composite. USA: Patterned Fiber Composites Inc, 2001.

127. Garvan F. The maple book. Boca Raton, London, New York, Washington DC: Chapman \& Hall/CRC, 2002.

128. Bonhomme J, Argüelles A, Castrillo MA, et al. Computational models for mode I composite fracture failure: the virtual crack closure technique versus the two-step extension method. Meccanica 2010; 45: 297-304.

129. Tian B, Li R and Zhong Y. Integral transform solutions to the bending problems of moderately thick rectangular plates with all edges free resting on elastic foundations. Appl Math Modell 2015; 39: 128-136. 


\section{Appendix I}

\section{Notation}

Latin symbols.

$$
\begin{aligned}
& \text { a Delamination length } \\
& b \quad \text { Plate width } \\
& \text { c Undelaminated length } \\
& g_{a} \quad \text { Set of displacement parameters } \\
& t_{b} \quad \text { Thickness of bottom plate } \\
& t_{i} \quad \text { Thickness of the ith ESL } \\
& t_{t} \quad \text { Thickness of top plate } \\
& u, v, w \quad \text { Displacement field components } \\
& u_{0}, v_{0} \quad \text { Global membrane displacements } \\
& u_{0 i}, v_{0 i} \quad \text { Local membrane displacements } \\
& z^{(i)} \quad \text { Local through the thickness coordinate } \\
& z_{R}^{(i)} \quad \text { Coordinate of the global reference plane in the ith } \\
& \text { ESL } \\
& z_{m}^{(i)}, z_{m+1}^{(i)} \quad \text { Local coordinates of the mth layer in the ith ESL } \\
& A_{p q} \quad \text { Extensional stiffness matrix } \\
& B_{p q} \quad \text { Coupling stiffness matrix } \\
& D_{p q} \quad \text { Bending stiffness matrix } \\
& E_{11}, E_{22}, E_{33} \quad \text { Moduli of elasticity in the } \mathrm{x}, \mathrm{y} \text { and } \mathrm{z} \text { directions } \\
& E_{p q}, F_{p q}, G_{p q}, H_{p q} \quad \text { Higher-order stiffness matrices } \\
& \text { F Vector of external load } \\
& \text { G Matrix exponential } \\
& G_{12}, G_{13}, G_{23} \quad \text { Shear moduli in the } \mathrm{x}-\mathrm{y}, \mathrm{x}-\mathrm{z} \text { and } \mathrm{y}-\mathrm{z} \text { planes } \\
& G_{\text {III }} \quad \text { Mode-III energy release rate } \\
& G_{\text {II }} \quad \text { Mode-II energy release rate } \\
& \text { H Vector of particular solution } \\
& J_{\text {III } \quad \text { Mode-III J-integral }} \\
& J_{\text {II }} \quad \text { Mode-II J-integral } \\
& K_{i j} \quad \text { Displacement multiplicator matrix } \\
& \hat{L}_{x}, \hat{L}_{x y}, \hat{L}_{x}, \hat{P}_{x y}, \hat{P}_{x y} \\
& \hat{M}_{x}, \hat{M}_{x y} \\
& M_{x}, M_{y}, M_{x y} \\
& N_{x}, N_{y}, N_{x y} \\
& P_{x}, P_{y}, P_{x y} \\
& Q_{0} \\
& Q_{n} \quad \text { Coefficient in trial function of external load } \\
& Q_{x}, Q_{y} \quad \text { Transverse shear forces } \\
& R_{x}, R_{y} \quad \text { Higher-order shear forces }
\end{aligned}
$$




$\begin{aligned} S_{x}, S_{y} & \begin{array}{l}\text { Higher-order shear forces } \\ \mathbf{T}\end{array} \\ U_{n}, V_{n}, W_{n} & \begin{array}{l}\text { System matrix } \\ \text { Function coefficients in trial function of displacement } \\ \text { parameters }\end{array} \\ U_{0 \delta n}, V_{0 \delta n} & \begin{array}{l}\text { Function coefficients in trial function of displacement } \\ \text { parameters }\end{array} \\ T_{y n}, Z_{x n}, Z_{y n} & \begin{array}{l}\text { Function coefficients in trial function of displacement } \\ \text { components } \\ \text { State vector }\end{array}\end{aligned}$

Greek symbols.

\begin{tabular}{|c|c|}
\hline$\gamma_{x z}, \gamma_{y z}$ & Transverse shear strains \\
\hline$\hat{\gamma}_{x y}$ & Conjugate shear strain \\
\hline$\delta u, \delta v, \delta w$ & Virtual displacement field components \\
\hline$\delta \psi_{(x j)}, \delta \psi_{(y) j}$ & $\begin{array}{l}\text { Vectors of virtual primary parameters in the } \mathrm{x}, \mathrm{y}, \mathrm{z} \\
\text { coordinate system }\end{array}$ \\
\hline$\varepsilon_{i j}$ & Strain tensor \\
\hline$\theta$ & Angle of rotation \\
\hline$\lambda$ & Third-order displacement term \\
\hline$\sigma_{\mathrm{ij}}$ & Stress tensor \\
\hline$v_{12}, v_{13}, v_{23}$ & Poisson's ratios in the $\mathrm{x}-\mathrm{y}, \mathrm{x}-\mathrm{z}$ and $\mathrm{y}-\mathrm{z}$ planes \\
\hline$\phi$ & Second-order displacement term \\
\hline$\Delta x, \Delta y, \Delta z$ & Size of crack tip elements \\
\hline$\Phi_{(x)}, \Phi_{(y)}$ & $\begin{array}{l}\text { Function coefficients in trial function of displacement } \\
\text { components }\end{array}$ \\
\hline$\psi_{(x) j}, \psi_{(y) j}$ & $\begin{array}{l}\text { Vectors of primary parameters in the } \mathrm{x}, \mathrm{y}, \mathrm{z} \text { coordi- } \\
\text { nate system }\end{array}$ \\
\hline$\psi_{(p)}$ & Vector of primary parameters \\
\hline
\end{tabular}




\section{Appendix 2}

Multiplicator matrix elements for SSDT

Table 7. Multiplicator matrix elements for the SSDT theory - Undelaminated region, scenario I: Core-core delamination.

\begin{tabular}{|c|c|c|c|c|c|c|c|}
\hline$[i, j]$ & $K_{i j}^{(0)}$ & $K_{i j}^{(I)}$ & $K_{i j}^{(2)}$ & {$[i, j]$} & $K_{i j}^{(0)}$ & $K_{i j}^{(I)}$ & $K_{i j}^{(2)}$ \\
\hline$[\mathrm{I}, \mathrm{I}]$ & $-\frac{3}{4} t_{1}$ & I & $\frac{1}{t_{1}}$ & {$[3,1]$} & 0 & 0 & 0 \\
\hline$[1,2]$ & $-z_{R}^{(2)}-\frac{1}{2} t_{2}$ & 0 & 0 & {$[3,2]$} & $-z_{R}^{(2)}+\frac{1}{2} t_{2}+\frac{1}{4} t_{3}$ & 0 & $-\frac{1}{t_{3}}$ \\
\hline$[1,3]$ & 0 & 0 & 0 & {$[3,3]$} & $\frac{1}{4} t_{3}$ & 1 & $\frac{1}{t_{3}}$ \\
\hline$[1,4]$ & $\frac{1}{4} t_{1}$ & 0 & $-\frac{1}{t_{1}}$ & {$[3,4]$} & 0 & 0 & 0 \\
\hline$[1,5]$ & $\frac{1}{4}\left(t_{2}-2 z_{R}^{(2)}\right)\left(t_{2}+2 z_{R}^{(2)}\right)$ & 0 & $0^{\tau_{1}}$ & {$[3,5]$} & $-\left(z_{R}^{(2)}\right)^{2}+\frac{1}{2} t_{2}^{2}+\frac{1}{4} t_{3} t_{2}$ & 0 & $-\frac{t_{2}}{t_{3}}$ \\
\hline$[1,6]$ & $\frac{1}{4} t_{1} t_{4}$ & 0 & $-\frac{t_{4}}{t_{1}}$ & {$[3,6]$} & 0 & 0 & 0 \\
\hline$[2,1]$ & 0 & 0 & 0 & {$[4,1]$} & 0 & 0 & 0 \\
\hline$[2,2]$ & $-z_{R}^{(2)}$ & I & 0 & {$[4,2]$} & $-z_{R}^{(2)}+\frac{1}{2} t_{2}$ & 0 & 0 \\
\hline$[2,3]$ & 0 & 0 & 0 & {$[4,3]$} & $t_{3}$ & 0 & 0 \\
\hline$[2,4]$ & 0 & 0 & 0 & {$[4,4]$} & $\frac{1}{2} t_{4}$ & 1 & 0 \\
\hline$[2,5]$ & $-\left(z_{R}^{(2)}\right)^{2}$ & 0 & 1 & {$[4,5]$} & $\frac{1}{4}\left(t_{2}-2 z_{R}^{(2)}\right)\left(t_{2}+2 z_{R}^{(2)}\right)$ & 0 & 0 \\
\hline$[2,6]$ & 0 & 0 & 0 & {$[4,6]$} & $-\frac{1}{4} t_{4}^{2}$ & 0 & I \\
\hline
\end{tabular}

Table 8. Multiplicator matrix elements for the SSDT theory - Undelaminated region, scenarios II and III: Face-core and face-face delamination.

\begin{tabular}{lllllllc}
\hline$[\mathrm{i}, j]$ & $K_{i j}^{(0)}$ & $K_{i j}^{(1)}$ & $K_{i j}^{(2)}$ & {$[i, j]$} & $K_{i j}^{(0)}$ & $K_{i j}^{(1)}$ & $K_{i j}^{(2)}$ \\
\hline$[1,1]$ & $-\frac{3}{4} t_{1}$ & $\mathrm{I}$ & $\frac{1}{t_{1}}$ & {$[3,1]$} & 0 & 0 & 0 \\
{$[1,2]$} & $-z_{R}^{(2)}-\frac{1}{2} t_{2}$ & 0 & 0 & {$[3,2]$} & $-z_{R}^{(2)}+\frac{1}{2} t_{2}$ & 0 & 0 \\
{$[1,3]$} & 0 & 0 & 0 & {$[3,3]$} & $\frac{3}{4} t_{3}$ & $\mathrm{I}$ & $-\frac{1}{t_{3}}$ \\
{$[1,4]$} & $\frac{1}{4} t_{1}$ & 0 & $-\frac{1}{t_{1}}$ & {$[3,4]$} & $-\frac{1}{4} t_{3}$ & 0 & $\frac{1}{t_{3}}$ \\
{$[1,5]$} & $\frac{1}{4}\left(t_{2}-2 z_{R}^{(2)}\right)\left(t_{2}+2 z_{R}^{(2)}\right)$ & 0 & 0 & {$[3,5]$} & $\frac{1}{4}\left(t_{2}-2 z_{R}^{(2)}\right)\left(t_{2}+2 z_{R}^{(2)}\right)$ & 0 & 0 \\
{$[1,6]$} & $\frac{1}{4} t_{1} t_{4}$ & 0 & $-\frac{t_{4}}{t_{1}}$ & {$[3,6]$} & $\frac{1}{4} t_{3} t_{4}$ & 0 & $-\frac{t_{4}}{t_{3}}$ \\
{$[2,1]$} & 0 & 0 & 0 & {$[4,1]$} & 0 & 0 & 0 \\
{$[2,2]$} & $-z_{R}^{(2)}$ & $\mathrm{I}$ & 0 & {$[4,2]$} & $-z_{R}^{(2)}+\frac{1}{2} t_{2}$ & 0 & 0 \\
{$[2,3]$} & 0 & 0 & 0 & {$[4,3]$} & $t_{3}$ & 1 & 0 \\
{$[2,4]$} & 0 & 0 & 0 & {$[4,4]$} & $\frac{1}{4} t_{4}$ & 0 \\
{$[2,5]$} & $-\left(z_{R}^{(2)}\right)^{2}$ & 0 & $I$ & {$[4,5]$} & $\frac{1}{4}\left(t_{2}-2 z_{R}^{(2)}\right)\left(t_{2}+2 z_{R}^{(2)}\right)$ & 0 & 0 \\
{$[2,6]$} & 0 & 0 & 0 & {$[4,6]$} & $-\frac{1}{4} t_{4}^{2}$ & 0 & 1
\end{tabular}


Table 9. Multiplicator matrix elements for the SSDT theory - Delaminated region, scenario I: Core-core delamination.

\begin{tabular}{|c|c|c|c|c|c|c|c|}
\hline$[i, j]$ & $K_{i j}^{(0)}$ & $K_{i j}^{(I)}$ & $K_{i j}^{(2)}$ & {$[i, j]$} & $K_{i j}^{(0)}$ & $K_{i j}^{(I)}$ & $K_{i j}^{(2)}$ \\
\hline$[\mathrm{I}, \mathrm{I}]$ & $-\frac{z_{R}^{(1)}\left(t_{1}+z_{R}^{(I)}\right)}{t_{1}}$ & I & $\frac{1}{t_{1}}$ & {$[3,1]$} & 0 & 0 & 0 \\
\hline$[1,2]$ & 0 & 0 & 0 & {$[3,2]$} & $\frac{1}{4} t_{3}$ & 0 & $-\frac{1}{t_{3}}$ \\
\hline$[1,3]$ & 0 & 0 & 0 & {$[3,3]$} & $-\frac{3}{4} t_{3}$ & I & $\frac{1}{t_{3}}$ \\
\hline$[1,4]$ & $\frac{\left(z_{R}^{(1)}\right)^{2}}{t_{1}}$ & 0 & $-\frac{1}{t_{1}}$ & {$[3,4]$} & $-z_{R}^{(4)}-\frac{1}{2} t_{4}$ & 0 & 0 \\
\hline$[I, 5]$ & 0 & 0 & 0 & {$[3,5]$} & $\frac{1}{4} t_{2} t_{3}$ & 0 & $-\frac{t_{2}}{t_{3}}$ \\
\hline$[1,6]$ & $\frac{\left(z_{R}^{(I)}\right)^{2} t_{4}}{t_{1}}$ & 0 & $-\frac{t_{4}}{t_{1}}$ & {$[3,6]$} & $\frac{\left(t_{4}-2 z_{R}^{(4)}\right)\left(t_{4}+2 z_{R}^{(4)}\right)}{4}$ & 0 & 0 \\
\hline$[2,1]$ & $\frac{\left(3 t_{1}+2 z_{R}^{(I)}\right)\left(t_{1}-2 z_{R}^{(I)}\right)}{4 t_{1}}$ & 0 & 0 & {$[4, I]$} & 0 & 0 & 0 \\
\hline$[2,2]$ & $\frac{1}{2} t_{2}$ & I & 0 & {$[4,2]$} & 0 & 0 & 0 \\
\hline$[2,3]$ & $0\left(t_{1}-2 z_{R}^{(I)}\right)\left(t_{1}+2 z_{R}^{(I)}\right)$ & 0 & 0 & {$[4,3]$} & 0 & 0 & 0 \\
\hline$[2,4]$ & $-\frac{1}{4 t_{1}}$ & 0 & 0 & {$[4,4]$} & $z_{0}$ & 1 & 0 \\
\hline$[2,5]$ & $-\frac{1}{4} t_{2}^{2}$ & 0 & 1 & {$[4,5]$} & 0 & 0 & 0 \\
\hline$[2,6]$ & $-\frac{t_{4}\left(t_{1}-2 z_{R}^{(I)}\right)\left(t_{1}+2 z_{R}^{(I)}\right)}{4 t_{1}}$ & 0 & 0 & {$[4,6]$} & $-\left(z_{R}^{(4)}\right)^{2}$ & 0 & I \\
\hline
\end{tabular}

Table 10. Multiplicator matrix elements for the SSDT theory - Delaminated region, scenario II: Face-core delamination.

\begin{tabular}{lllllllc}
\hline$[\mathrm{i}, \mathrm{j}]$ & $K_{i j}^{(0)}$ & $K_{i j}^{(I)}$ & $K_{i j}^{(2)}$ & {$[\mathrm{i}, j]$} & $K_{i j}^{(0)}$ & $K_{i j}^{(1)}$ & $K_{i j}^{(2)}$ \\
\hline$[1,1]$ & $-\frac{z_{R}^{(I)}\left(t_{1}+z_{R}^{(1)}\right)}{t_{1}}$ & 1 & $\frac{1}{t_{1}}$ & {$[3,1]$} & 0 & 0 & 0 \\
{$[1,2]$} & 0 & 0 & 0 & {$[3,2]$} & 0 & 0 & 0 \\
{$[1,3]$} & 0 & 0 & 0 & {$[3,3]$} & $-\frac{1}{4} t_{3}$ & 1 & $-\frac{1}{t_{3}}$ \\
{$[1,4]$} & $\frac{\left(z_{R}^{(1)}\right)^{2}}{t_{1}}$ & 0 & $-\frac{1}{t_{1}}$ & {$[3,4]$} & $-z_{R}^{(4)}-\frac{1}{4} t_{3}-\frac{1}{2} t_{4}$ & 0 & $\frac{1}{t_{3}}$ \\
{$[1,5]$} & 0 & 0 & 0 & {$[3,5]$} & 0 & 0 & 0 \\
\hline
\end{tabular}


Table 10. Continued

\begin{tabular}{|c|c|c|c|c|c|c|c|}
\hline$[i, j]$ & $K_{i j}^{(0)}$ & $K_{i j}^{(1)}$ & $K_{i j}^{(2)}$ & {$[i, j]$} & $K_{i j}^{(0)}$ & $K_{i j}^{(1)}$ & $K_{i j}^{(2)}$ \\
\hline$[1,6]$ & $\frac{\left(z_{R}^{(1)}\right)^{2} t_{4}}{t_{1}}$ & 0 & $-\frac{t_{4}}{t_{1}}$ & {$[3,6]$} & $\frac{1}{4} t_{3} t_{4}-\left(z_{R}^{(4)}\right)^{2}+\frac{1}{4} t_{4}^{2}$ & 0 & $-\frac{t_{4}}{t_{3}}$ \\
\hline$[2, I]$ & $\frac{\left(3 t_{1}+2 z_{R}^{(I)}\right)\left(t_{1}-2 z_{R}^{(I)}\right)}{4 t_{1}}$ & 0 & 0 & {$[4, I]$} & 0 & 0 & 0 \\
\hline$[2,2]$ & $\frac{1}{2} t_{2}$ & I & 0 & {$[4,2]$} & 0 & 0 & 0 \\
\hline$[2,3]$ & ${ }^{0}\left(t_{1}-2 z_{R}^{(I)}\right)\left(t_{1}+2 z_{R}^{(I)}\right)$ & 0 & 0 & {$[4,3]$} & 0 & 0 & 0 \\
\hline$[2,4]$ & $-\frac{\left(t_{1}-2 L^{2}\right)\left(t_{1}+2 L_{R}\right)}{4 t_{1}}$ & 0 & 0 & {$[4,4]$} & $-z_{R}^{(4)}$ & I & 0 \\
\hline$[2,5]$ & $-\frac{1}{4} t_{2}^{2}$ & 0 & I & {$[4,5]$} & 0 & 0 & 0 \\
\hline$[2,6]$ & $-\frac{t_{4}\left(t_{1}-2 z_{R}^{(I)}\right)\left(t_{1}+2 z_{R}^{(1)}\right)}{4 t_{1}}$ & 0 & 0 & {$[4,6]$} & $-\left(z_{R}^{(4)}\right)^{2}$ & 0 & I \\
\hline
\end{tabular}

\section{Appendix 3}

Multiplicator matrix elements for TSDT

Table II. Multiplicator matrix elements for the SSDT theory - Delaminated region, scenario III: Face-face delamination.

\begin{tabular}{|c|c|c|c|c|c|c|c|}
\hline$\underline{[i, j]}$ & $K_{i j}^{(0)}$ & $K_{i j}^{(I)}$ & $K_{i j}^{(2)}$ & {$[i, j]$} & $K_{i j}^{(0)}$ & $K_{i j}^{(I)}$ & $K_{i j}^{(2)}$ \\
\hline$[1,1]$ & $-\frac{3}{4} t_{1}$ & I & $\frac{1}{t_{1}}$ & {$[3,1]$} & 0 & 0 & 0 \\
\hline$[1,2]$ & $-z_{R}^{(2)}-\frac{1}{2} t_{2}$ & 0 & 0 & {$[3,2]$} & $-z_{R}^{(1)}+\frac{1}{2} t_{2}$ & 0 & 0 \\
\hline$[1,3]$ & 0 & 0 & 0 & {$[3,3]$} & $\frac{3}{4} t_{3}$ & 1 & $-\frac{1}{t_{3}}$ \\
\hline$[1,4]$ & $\frac{1}{4} t_{1}$ & 0 & $-\frac{1}{t_{1}}$ & {$[3,4]$} & $-\frac{1}{4} t_{3}$ & 0 & $\frac{1}{t_{3}}$ \\
\hline$[1,5]$ & $\frac{1}{4}\left(t_{2}-2 z_{R}^{(I)}\right)\left(t_{2}+2 z_{R}^{(I)}\right)$ & 0 & 0 & {$[3,5]$} & $\frac{1}{4}\left(t_{2}-2 z_{R}^{(I)}\right)\left(t_{2}+2 z_{R}^{(I)}\right)$ & 0 & 0 \\
\hline$[1,6]$ & $\frac{1}{4} t_{1} t_{4}$ & 0 & $-\frac{t_{4}}{t_{1}}$ & {$[3,6]$} & $\frac{1}{4} t_{3} t_{4}$ & 0 & $\frac{t_{4}}{t_{3}}$ \\
\hline$[2,1]$ & 0 & 0 & 0 & {$[4,1]$} & 0 & 0 & 0 \\
\hline$[2,2]$ & $-z_{R}^{(1)}$ & I & 0 & {$[4,2]$} & 0 & 0 & 0 \\
\hline$[2,3]$ & 0 & 0 & 0 & {$[4,3]$} & 0 & 0 & 0 \\
\hline$[2,4]$ & 0 & 0 & 0 & {$[4,4]$} & $-z_{R}^{(4)}$ & 1 & 0 \\
\hline$[2,5]$ & $-\left(z_{R}^{(I)}\right)^{2}$ & 0 & I & {$[4,5]$} & 0 & 0 & 0 \\
\hline$[2,6]$ & 0 & 0 & 0 & {$[4,6]$} & $-\left(z_{R}^{(4)}\right)^{2}$ & 0 & I \\
\hline
\end{tabular}


Table 12. Multiplicator matrix elements for the TSDT theory - Undelaminated region, scenario I: Core-core delamination.

\begin{tabular}{|c|c|c|c|c|c|c|c|c|c|}
\hline$[i, j]$ & $K_{i j}^{(0)}$ & $K_{i j}^{(I)}$ & $K_{i j}^{(2)}$ & $K_{i j}^{(3)}$ & {$[i, j]$} & $K_{i j}^{(0)}$ & $K_{i j}^{(1)}$ & $K_{i j}^{(2)}$ & $K_{i j}^{(3)}$ \\
\hline$[\mathrm{I}, \mathrm{I}]$ & $-\frac{3}{4} t_{1}$ & I & $\frac{1}{t_{1}}$ & 0 & {$[3,1]$} & 0 & 0 & 0 & 0 \\
\hline$[1,2]$ & $-z_{R}^{(2)}-\frac{1}{2} t_{2}$ & 0 & 0 & 0 & {$[3,2]$} & $-z_{R}^{(2)}+\frac{1}{2} t_{2}+\frac{1}{3} t_{3}$ & 0 & $-\frac{2}{t_{3}}$ & $-\frac{4}{3 t_{3}^{2}}$ \\
\hline$[1,3]$ & 0 & 0 & 0 & 0 & {$[3,3]$} & $\frac{1}{6} t_{3}$ & I & $\frac{2}{t_{3}}$ & $\frac{4}{3 t_{3}^{2}}$ \\
\hline$[1,4]$ & $\frac{1}{4} t_{1}$ & 0 & $-\frac{1}{t_{1}}$ & 0 & {$[3,4]$} & 0 & 0 & 0 & 0 \\
\hline$[1,5]$ & $\frac{1}{4}\left(t_{2}-2 z_{R}^{(2)}\right)\left(t_{2}+2 z_{R}^{(2)}\right)$ & 0 & 0 & 0 & {$[3,5]$} & $\begin{array}{r}-\left(z_{R}\right)+\frac{-}{4} \\
+\frac{t_{3} t_{2}}{2}+t_{3}^{2}\end{array}$ & 0 & $-\frac{t 3+2 t_{2}}{t_{3}}$ & $-\frac{4\left(t_{2}+t_{3}\right)}{3 t_{3}^{2}}$ \\
\hline$[1,6]$ & $\frac{1}{4} t_{1} t_{4}$ & 0 & $-\frac{t_{4}}{t_{1}}$ & 0 & {$[3,6]$} & $0+\frac{5}{3}+\frac{1}{12}$ & 0 & 0 & 0 \\
\hline$[1,7]$ & $\begin{array}{l}-\frac{\left(t_{2}+2 z_{R}^{(2)}\right)}{8} \\
\times\left(4\left(z_{R}^{(2)}\right)^{2}-2 t_{2} z_{R}^{(2)}+t_{2}^{2}\right)\end{array}$ & 0 & 0 & 0 & {$[3,7]$} & $\begin{array}{c}-\left(z_{R}^{(2)}\right)^{3}+\frac{t_{3} t_{2}^{2}}{4} \\
+\frac{t_{3}^{2} t_{2}}{8}+\frac{t_{2}^{3}}{8}\end{array}$ & 0 & $-\frac{3}{2} \frac{\left(t 3+t_{2}\right) t_{2}}{t_{3}}$ & $-\frac{t_{2}\left(t_{2}+t_{3}\right)}{t_{3}^{2}}$ \\
\hline$[2,1]$ & 0 & 0 & 0 & 0 & {$[4,1]$} & 0 & 0 & 0 & 0 \\
\hline$[2,2]$ & $-z_{R}^{(2)}$ & 1 & 0 & 0 & {$[4,2]$} & $-z_{R}^{(2)}+\frac{1}{2} t_{2}-\frac{1}{3} t_{3}$ & 0 & 0 & 0 \\
\hline$[2,3]$ & 0 & 0 & 0 & 0 & {$[4,3]$} & $\frac{4}{3} t_{3}$ & 0 & 0 & 0 \\
\hline$[2,4]$ & 0 & 0 & 0 & 0 & {$[4,4]$} & ${ }^{\frac{1}{2}} t_{4} t_{3}\left(t_{2}+t_{3}\right)$ & I & 0 & 0 \\
\hline$[2,5]$ & $-\left(z_{R}^{(2)}\right)^{2}$ & 0 & I & 0 & {$[4,5]$} & $+\frac{t_{2}^{2}}{4}-\left(z_{R}^{(2)}\right)^{2}$ & 0 & 0 & 0 \\
\hline$[2,6]$ & 0 & 0 & 0 & 0 & {$[4,6]$} & $-\frac{1}{4} t_{4}^{2}$ & 0 & I & 0 \\
\hline$[2,7]$ & $-\left(z_{R}^{(2)}\right)^{3}$ & 0 & 0 & 1 & {$[4,7]$} & $\begin{array}{r}-\frac{t_{3} t_{2}}{2}\left(\frac{t_{2}}{2}+t_{3}\right) \\
+\frac{t_{2}^{3}}{8}-\left(z_{R}^{(2)}\right)^{3}\end{array}$ & 0 & I & 0 \\
\hline
\end{tabular}


Table 13. Multiplicator matrix elements for the TSDT theory - Undelaminated region, scenarios II and III: Face-core and face-face delamination.

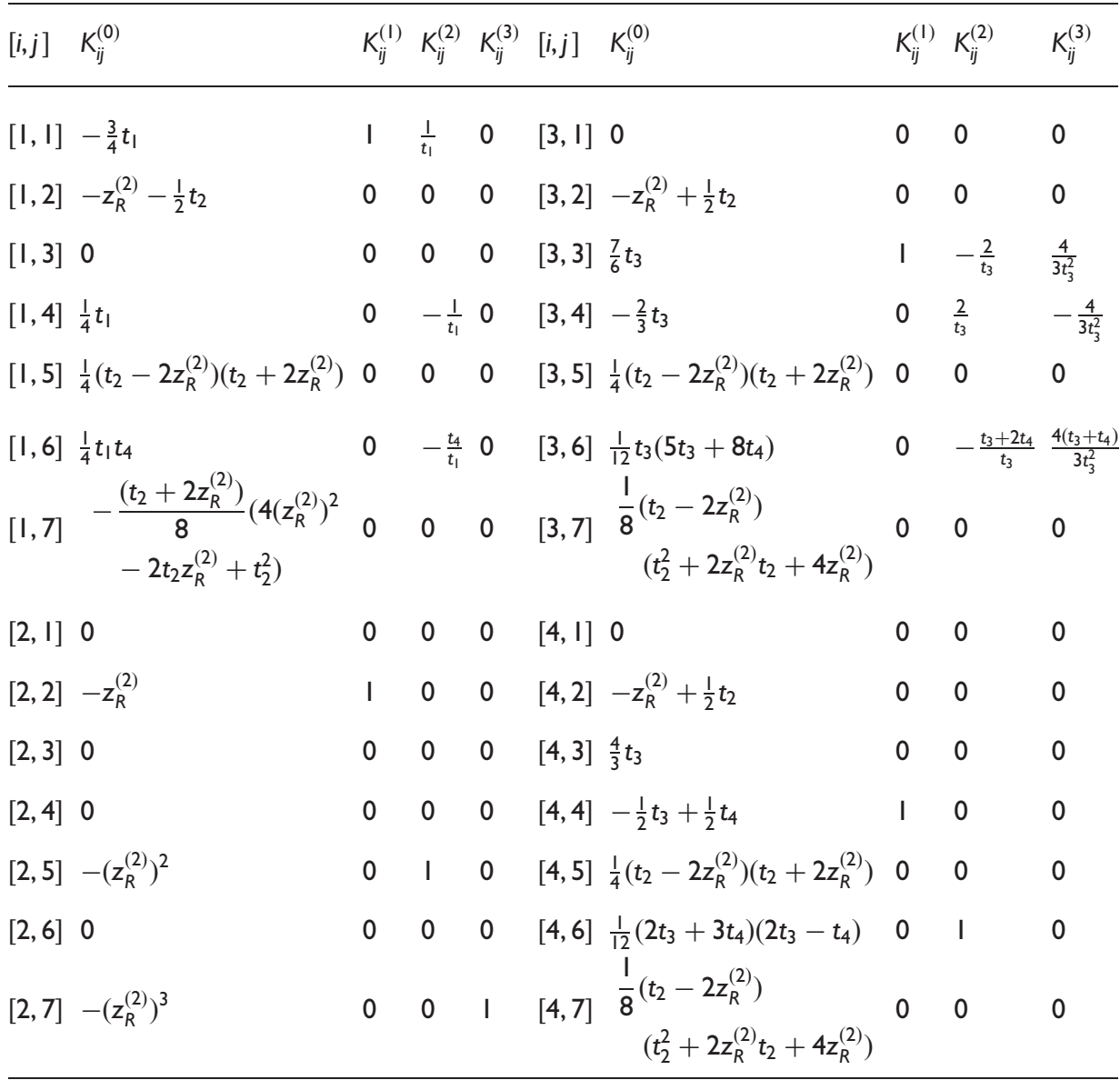

Table 14. Multiplicator matrix elements for the TSDT theory - Delaminated region, scenario I: Core-core delamination.

\begin{tabular}{llllllllll}
\hline$[i, j]$ & $K_{i j}^{(0)}$ & $K_{i j}^{(I)}$ & $K_{i j}^{(2)}$ & $K_{i j}^{(3)}$ & {$[i, j]$} & $K_{i j}^{(0)}$ & $K_{i j}^{(1)}$ & $K_{i j}^{(2)}$ & $K_{i j}^{(3)}$ \\
\hline$[I, I]$ & $-\frac{z_{R}^{(1)}\left(t_{1}+z_{R}^{(1)}\right)}{t_{1}}$ & 1 & $\frac{1}{t_{1}}$ & 0 & {$[3, I]$} & 0 & 0 & 0 & 0 \\
{$[1,2]$} & 0 & 0 & 0 & 0 & {$[3,2]$} & $\frac{1}{4} t_{3}$ & 0 & $-\frac{1}{t_{3}}$ & 0 \\
{$[1,3]$} & 0 & 0 & 0 & 0 & {$[3,3]$} & $-\frac{3}{4} t_{3}$ & 1 & $\frac{1}{t_{3}}$ & 0 \\
{$[1,4]$} & $\frac{\left(z_{R}^{(1)}\right)^{2}}{t_{1}}$ & 0 & $-\frac{1}{t_{1}}$ & 0 & {$[3,4]$} & $-z_{R}^{(4)}-\frac{1}{2} t_{4}$ & 0 & 0 & 0 \\
\hline
\end{tabular}


Table I4. Continued

\begin{tabular}{llllllllll}
\hline$[i, j]$ & $K_{i j}^{(0)}$ & $K_{i j}^{(1)}$ & $K_{i j}^{(2)}$ & $K_{i j}^{(3)}$ & {$[i, j]$} & $K_{i j}^{(0)}$ & $K_{i j}^{(1)}$ & $K_{i j}^{(2)}$ & $K_{i j}^{(3)}$ \\
\hline$[1,5]$ & 0 & 0 & 0 & 0 & {$[3,5]$} & $\frac{1}{4} t_{3} t_{2}$ & 0 & $-\frac{t_{2}}{t_{3}}$ & 0 \\
{$[1,6]$} & $\frac{\left(z_{R}^{(1)}\right)^{2} t_{4}}{t_{1}}$ & 0 & $-\frac{t_{4}}{t_{1}}$ & 0 & {$[3,6]$} & $\frac{\left(t_{4}-2 z_{R}^{(4)}\right)\left(t_{4}+2 z_{R}^{(4)}\right)}{4}$ & 0 & 0 & 0 \\
{$[1,7]$} & 0 & 0 & 0 & 0 & {$[3,7]$} & $\frac{3}{16} t_{3} t_{2}^{2}$ & 0 & $-\frac{3}{4} t_{2}^{2}$ & 0 \\
{$[1,8]$} & 0 & 0 & 0 & 0 & {$[3,8]$} & $-\frac{5}{16} t_{3}^{3}$ & 0 & $\frac{3}{4} t_{3}$ & 1 \\
{$[2,1]$} & $\frac{\left(3 t_{1}+2 z_{R}^{(1)}\right)\left(t_{1}-2 z_{R}^{(1)}\right)}{4 t_{1}}$ & 0 & 0 & 0 & {$[4,1]$} & 0 & 0 & 0 & 0 \\
{$[2,2]$} & $\frac{1}{2} t_{2}$ & 1 & 0 & 0 & {$[4,2]$} & 0 & 0 & 0 & 0 \\
{$[2,3]$} & 0 & 0 & 0 & 0 & {$[4,3]$} & 0 & 0 & 0 & 0 \\
{$[2,4]$} & $-\frac{\left(t_{1}-2 z_{R}^{(1)}\right)\left(t_{1}+2 z_{R}^{(1)}\right)}{4 t_{1}}$ & 0 & 0 & 0 & {$[4,4]$} & $-z_{R}^{(4)}$ & 1 & 0 & 0 \\
{$[2,5]$} & $-\frac{1}{4} t_{2}^{2}$ & 0 & 1 & 0 & {$[4,5]$} & 0 & 0 & 0 & 0 \\
{$[2,6]$} & $-\frac{t_{4}\left(t_{1}-2 z_{R}^{(1)}\right)\left(t_{1}+2 z_{R}^{(1)}\right)}{4 t_{1}}$ & 0 & 0 & 0 & {$[4,6]$} & $-\left(z_{R}^{(4)}\right)^{2}$ & 0 & 1 & 0 \\
{$[2,7]$} & $\frac{1}{8} t_{2}^{3}$ & 0 & 0 & 1 & {$[4,7]$} & 0 & 0 & 0 & 0 \\
{$[2,8]$} & 0 & 0 & 0 & 0 & {$[4,8]$} & 0 & 0 & 0 & 0 \\
\hline
\end{tabular}

Table I5. Multiplicator matrix elements for the TSDT theory - Delaminated region, scenario II: Face-core delamination.

\begin{tabular}{|c|c|c|c|c|c|c|c|c|c|}
\hline$[i, j]$ & $K_{i j}^{(0)}$ & $K_{i j}^{(1)}$ & $K_{i j}^{(2)}$ & $K_{i j}^{(3)}$ & {$[i, j]$} & $K_{i j}^{(0)}$ & $K_{i j}^{(I)}$ & $K_{i j}^{(2)}$ & $K_{i j}^{(3)}$ \\
\hline$[1,1]$ & $-\frac{z_{R}^{(1)}\left(t_{1}+z_{R}^{(1)}\right)}{t_{1}}$ & I & $\frac{1}{t_{1}}$ & 0 & {$[3,1]$} & 0 & 0 & 0 & 0 \\
\hline$[1,2]$ & 0 & 0 & 0 & 0 & {$[3,2]$} & 0 & 0 & 0 & 0 \\
\hline$[1,3]$ & 0 & 0 & 0 & 0 & {$[3,3]$} & $-\frac{1}{6} t_{3}$ & I & $-\frac{2}{t_{3}}$ & $\frac{4}{3 t_{3}^{2}}$ \\
\hline$[1,4]$ & $\frac{\left(z_{R}^{(1)}\right)^{2}}{t_{1}}$ & 0 & $-\frac{1}{t_{1}}$ & 0 & {$[3,4]$} & $-z_{R}^{(4)}-\frac{1}{3} t_{3}-\frac{1}{2} t_{4}$ & 0 & $\frac{2}{t_{3}}$ & $-\frac{4}{3 t_{3}^{2}}$ \\
\hline$[1,5]$ & 0 & 0 & 0 & 0 & {$[3,5]$} & $\begin{array}{l}0 \\
1\end{array}$ & 0 & 0 & 0 \\
\hline$[1,6]$ & $\frac{\left(z_{R}^{(1)}\right)^{2} t_{4}}{t_{t}}$ & 0 & $-\frac{t_{4}}{t_{1}}$ & 0 & {$[3,6]$} & $\overline{3}^{\tau_{3} \tau_{4}+\overline{12}^{\tau_{3}}}$ & 0 & $-\frac{t_{3}+2 t_{4}}{t_{3}}$ & $\frac{4}{3} \frac{t_{4}+t_{3}}{t^{2}}$ \\
\hline$[1,7]$ & 0 & 0 & 0 & 0 & {$[3,7]$} & $0+-\left(z_{R}^{(4)}\right)^{2}+\frac{1}{4} t_{4}^{2}$ & 0 & $0^{i 3}$ & \\
\hline$[2,1]$ & $\frac{\left(3 t_{1}+2 z_{R}^{(1)}\right)\left(t_{1}-2 z_{R}^{(1)}\right)}{4 t_{1}}$ & 0 & 0 & 0 & {$[4, I]$} & 0 & 0 & 0 & 0 \\
\hline$[2,2]$ & $\frac{1}{2} t_{2}$ & I & 0 & 0 & {$[4,2]$} & 0 & 0 & 0 & 0 \\
\hline$[2,3]$ & 0 & 0 & 0 & 0 & {$[4,3]$} & 0 & 0 & 0 & 0 \\
\hline$[2,4]$ & $-\frac{\left(t_{1}-2 z_{R}^{(i)}\right)\left(t_{1}+2 z_{R}^{(1)}\right)}{4 t_{1}}$ & 0 & 0 & 0 & {$[4,4]$} & $-z_{R}^{(4)}$ & I & 0 & 0 \\
\hline$[2,5]$ & $-\frac{1}{4} t_{2}^{2}$ & 0 & I & 0 & {$[4,5]$} & 0 & 0 & 0 & 0 \\
\hline$[2,6]$ & $-\frac{t_{4}\left(t_{1}-2 z_{R}^{(1)}\right)\left(t_{1}+2 z_{R}^{(1)}\right)}{4 t_{1}}$ & 0 & 0 & 0 & {$[4,6]$} & $-\left(z_{R}^{(4)}\right)^{2}$ & 0 & I & 0 \\
\hline$[2,7]$ & $\frac{1}{8} t_{2}^{3}$ & 0 & 0 & I & {$[4,7]$} & 0 & 0 & 0 & 0 \\
\hline
\end{tabular}


Table 16. Multiplicator matrix elements for the TSDT theory - Delaminated region, scenario III: Face-face delamination.

\begin{tabular}{|c|c|c|c|c|c|c|c|c|c|}
\hline$\overline{[i, j]}$ & $K_{i j}^{(0)}$ & $K_{i j}^{(I)}$ & $K_{i j}^{(2)}$ & $K_{i j}^{(3)}$ & {$[i, j]$} & $K_{i j}^{(0)}$ & $K_{i j}^{(I)}$ & $K_{i j}^{(2)}$ & $K_{i j}^{(3)}$ \\
\hline$[I, I]$ & $-\frac{z_{R}^{(1)}\left(t_{1}+z_{R}^{(1)}\right)}{t_{1}}$ & I & $\frac{1}{t_{1}}$ & 0 & {$[3,1]$} & $-\frac{\left(t_{1}-2 z_{R}^{(I)}\right)\left(3 t_{1}+2 z_{R}^{(1)}\right)}{4 t_{1}}$ & 0 & 0 & 0 \\
\hline$[1,2]$ & 0 & 0 & 0 & 0 & {$[3,2]$} & $t_{2}$ & 0 & 0 & 0 \\
\hline$[1,3]$ & 0 & 0 & 0 & 0 & {$[3,3]$} & & I & $-\frac{2}{t_{3}}$ & $\frac{4}{3 t^{2}}$ \\
\hline$[1,4]$ & $\frac{\left(z_{R}^{(1)}\right)^{2}}{t_{1}}$ & 0 & $-\frac{1}{t_{1}}$ & 0 & {$[3,4]$} & $-\frac{8 t_{3} t_{1}-12\left(z_{R}^{(1)}\right)^{2}+3 t_{1}^{2}}{12 t_{1}}$ & 0 & ${\frac{2}{t_{3}}}^{{ }^{3}}$ & $-\frac{4}{3 t^{2}}$ \\
\hline$[1,5]$ & 0 & 0 & 0 & 0 & {$[3,5]$} & 0 & 0 & 0 & 0 \\
\hline$[1,6]$ & $\frac{\left(z_{R}^{(1)}\right)^{2} t_{4}}{t_{1}}$ & 0 & $-\frac{t_{4}}{t_{1}}$ & 0 & {$[3,6]$} & $\frac{8 t_{3} t_{1} t_{4}+5 t_{3}^{2} t_{1}+12\left(z_{R}^{(1)}\right)^{2} t_{4}-3 t_{1}^{2} t_{4}}{12 t_{1}}$ & 0 & $-\frac{t_{3}+2 t_{4}}{t_{3}}$ & $\frac{4}{3} \frac{t_{4}+t_{3}}{t_{3}^{2}}$ \\
\hline$[1,7]$ & 0 & 0 & 0 & 0 & {$[3,7]$} & $\frac{1}{4} t_{2}^{3}$ & 0 & 0 & 0 \\
\hline$[2, I]$ & $\frac{\left(3 t_{1}+2 z_{R}^{(1)}\right)\left(t_{1}-2 z_{R}^{(1)}\right)}{4 t_{1}}$ & 0 & 0 & 0 & {$[4, I]$} & 0 & 0 & 0 & 0 \\
\hline$[2,2]$ & $\frac{1}{2} t_{2}$ & I & 0 & 0 & {$[4,2]$} & 0 & 0 & 0 & 0 \\
\hline$[2,3]$ & 0 & 0 & 0 & 0 & {$[4,3]$} & 0 & 0 & 0 & 0 \\
\hline$[2,4]$ & $-\frac{\left(t_{1}-2 z_{R}^{(1)}\right)\left(t_{1}+2 z_{R}^{(1)}\right)}{4 t_{1}}$ & 0 & 0 & 0 & {$[4,4]$} & $-z_{R}^{(4)}$ & I & 0 & 0 \\
\hline$[2,5]$ & $-\frac{1}{4} t_{2}^{2}$ & 0 & 1 & 0 & {$[4,5]$} & 0 & 0 & 0 & 0 \\
\hline$[2,6]$ & $-\frac{t_{4}\left(t_{1}-2 z_{R}^{(1)}\right)\left(t_{1}+2 z_{R}^{(1)}\right)}{4 t_{1}}$ & 0 & 0 & 0 & {$[4,6]$} & $-\left(z_{R}^{(4)}\right)^{2}$ & 0 & I & 0 \\
\hline$[2,7]$ & $\frac{1}{8} t_{2}^{3}$ & 0 & 0 & I & {$[4,7]$} & 0 & 0 & 0 & 0 \\
\hline
\end{tabular}

